\title{
Simulation of Fiber Fuse Phenomenon in Single-Mode Optical Fibers
}

\author{
Yoshito Shuto \\ Additional information is available at the end of the chapter
}

http://dx.doi.org/10.5772/58959

\section{Introduction}

By utilizing dense wavelength-division-multiplexed (DWDM) transmission systems using an optical-fiber amplifier, large amount of data can be exchanged at a rate of over $60 \mathrm{Tbit} / \mathrm{s}$ [1]. In connection with this achievement, the danger of the "fiber fuse phenomenon" occurring has been pointed out. This occurs when high-power ( $\mathrm{W}$ order) optical signals are transmitted in an optical-fiber cable [2].

The fiber fuse phenomenon was first observed in 1987 by British investigators [3]-[6]. A fiber fuse can be generated by bringing the end of a fiber into contact with an absorbing material, or melting a small region of a fiber by using an arc discharge of a fusion splice machine [3]. If a fiber fuse is generated, an intense blue-white flash occurs in the fiber core, and this flash propagates along the core in the direction of the optical power source at a velocity on the order of $1 \mathrm{~m} / \mathrm{s}$ (see Figure 1). Fuses are terminated by gradually reducing the laser power to provide a termination threshold at which the energy balance at a fuse is broken.

When a fiber fuse is generated, the core layer in which the fuse propagates is seriously damaged, and the damaged fiber cannot be used in an optical communication system. The damage is made manifest by periodic or nonperiodic bullet-shaped cavities left in the core [7]-[13]. It was found that molecular oxygen was released and remained in the cavities while maintaining high pressure (about 4 atmospheres) at room temperature [4].

Several review articles [14], [15], [16] and a book [17] have been recently published, which cover many aspects of the current understanding of the fiber fuse.

Most experimental results of fiber fuse generation have focused on an intensity of 0.35-25 $\mathrm{MW} / \mathrm{cm}^{2}$ [3]-[13], [18]-[39]. This is many orders of magnitude below the intrinsic damage limit for silica, which exceeds $10 \mathrm{GW} / \mathrm{cm}^{2}$ [3]. The threshold power for an SMF required to generate and / or terminate a fiber fuse was estimated at about 1.0 [7], 1.19 [37], 1.33 [37], and $1.4 \mathrm{~W}[30]$ at $\lambda_{0}=1.064,1.31,1.48$, and $1.56 \mu \mathrm{m}$, respectively. 


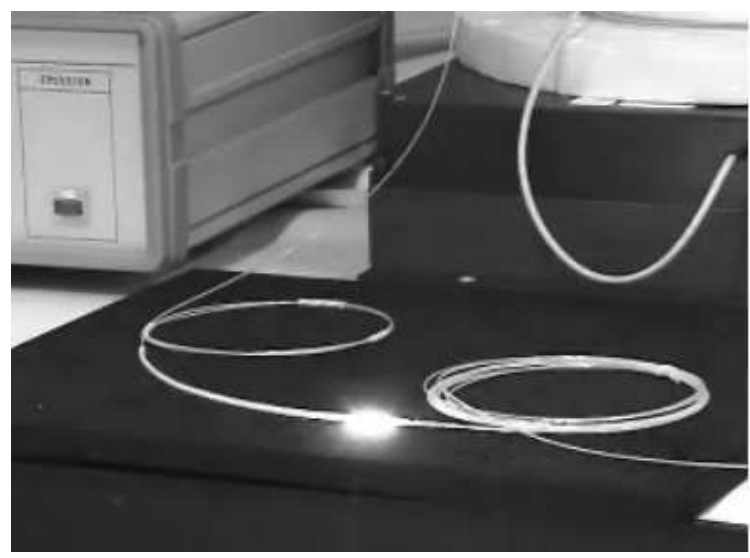

Figure 1. Fiber fuse phenomenon.

On the other hand, the fiber fuse effect in a microstructured optical fiber, in which thirty air holes are arranged around the fiber center, was reported by Dianov et al. [40]. No propagation of the fiber fuse was observed at the power of $\leq 3 \mathrm{~W}$ and $\lambda_{0}=0.5 \mu \mathrm{m}$. This threshold power $(3 \mathrm{~W})$ was an order of magnitude higher than that of a conventional fiber. They also reported that the propagation of the fiber fuse was not observed when the laser light of up to $9 \mathrm{~W}$ and $\lambda_{0}=1.064 \mu \mathrm{m}$ entered in the microstructured optical fiber.

It has recently been reported that a hole-assisted fiber (HAF) [41], in which several air holes are arranged near the core of the optical fiber, exhibits high tolerance to fiber fuses [42]-[51]. The fiber fuse propagation in a HAF is affected by both the diameter of an inscribed circle linking the air holes $\left(D_{\text {hole }}\right)$ and the diameter of the air hole $\left(d_{h}\right)$ (see Figure 2$)$.
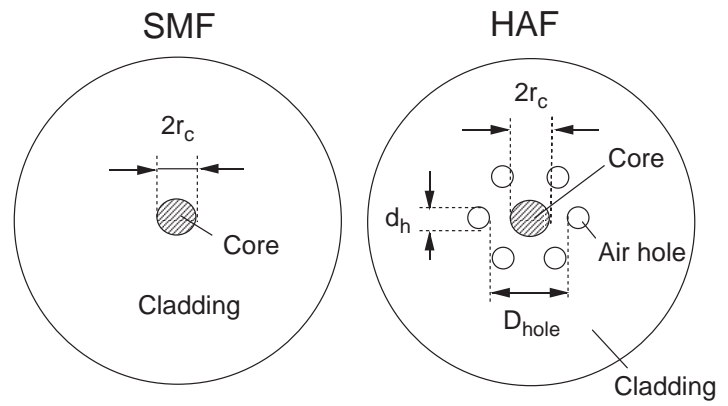

Figure 2. Schematic view of SMF and HAF.

No propagation of fiber fuse was observed in HAFs with $d_{h}=r_{c}=4.5 \mu \mathrm{m}$ and a ratio $R_{h}$ of the $D_{\text {hole }}$ to the core diameter $\left(2 r_{c}\right)$ of 2 or less when the laser power $P_{0}$ of 13.5 and/or 15.6 $\mathrm{W}$ at $\lambda_{0}=1.48+1.55 \mu \mathrm{m}$ was incident to HAFs [43], [45], [46].

Takenaga et al. investigated the power dependence of penetration length at a splice point of SMF and the HAF with $d_{h}$ of about 16.3-16.9 $\mu \mathrm{m}$ and $R_{h}$ of about 2.3, called "HAF2 $"$ " [42], 
[47]. The fiber fuse propagation immediately stopped in HAF2 + for $P_{0}$ of 2.0-8.1 $\mathrm{W}$ at $\lambda_{0}$ $=1.55 \mu \mathrm{m}$, where the penetration length was maintained constant (about $120 \mu \mathrm{m}$ ). But the penetration length in $\mathrm{HAF} 2+$ increased by nearly $600 \mu \mathrm{m}$ when $P_{0}$ decreased from $2.0 \mathrm{~W}$ to $1.5 \mathrm{~W}$.

They supposed that an inner ring area, which was observed around the cavities after fiber fuse propagation, was the trail of glass being melted. $D_{\text {melted }}$ defined as the diameter of melting area (see Fugure 3) was considered as the radial size of plasma generated in the fiber fuse.

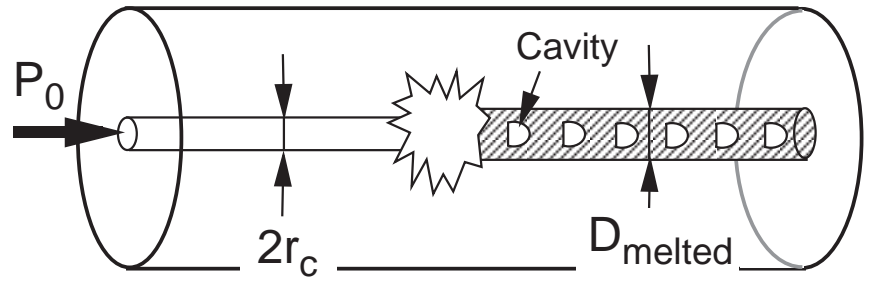

Figure 3. Schematic view of damaged SMF.

$D_{\text {melted }}$ of HAF2 + was maintained constant (about 20-22 $\mu \mathrm{m}$ ) in the $P_{0}$ range of 2.0-8.1 W, and decreased with decreasing $P_{0}$ in the $P_{0}$ range of 1.33-2.0 W [42], [47]. The constant $D_{\text {melted }}$ value (about 20-22 $\mu \mathrm{m}$ ) was almost equal to the $D_{\text {hole }}$ value $(21.2 \mu \mathrm{m})$ of HAF2 + in the $P_{0}$ range of 2.0-8.1 W. Therefore, an increase in penetration length observed in HAF2 + for $P_{0} \leq 2 \mathrm{~W}$ was considered to be induced by the reduction of plasma size. On the other hand, $D_{\text {melted }}$ of an SMF increased monotonously with increasing $P_{0}$ in the $P_{0}$ range of 4-14 $\mathrm{W}$ [46].

Several hypotheses have been put forward to explain the fiber fuse phenomenon. These include a chemical reaction involving the exothermal formation of germanium (Ge) defects [18], self-propelled self-focusing [3], thermal lensing of the light in the fiber via a solitary thermal shock wave [5], and the radiative collision of $\mathrm{SiO}$ and O complexes [52]-[55].

The similarities between the fiber fuse propagation and the combustion flame propagation were pointed out by Facão et al. [56], Todoroki [15], and Ankiewicz [57]. A fast detonation-like mode of fiber fuse propagation with a velocity of $3.2 \mathrm{~km} / \mathrm{s}$ was observed under intense laser radiation intensity of $4,000 \mathrm{MW} / \mathrm{cm}^{2}$ [58]. Combustion processes, including thermal self-ignition, can be mathematically expressed by the reaction-diffusion equations for temperature and fuel concentration [59], [60], [61]. If the reaction term for fuel concentration in these equations is replaced by the heat source term resulting from light absorption, the fiber fuse propagation can be described by solving the equations [56], [57], [62].

The optical absorption coefficient $\alpha$ of a fiber core at high temperatures is closely related to the generation of the fiber fuse. Kashyap reported a remarkable increase in the $\alpha$ value of a Ge-doped silica core above the critical temperature $T_{0}(\sim 1,323 \mathrm{~K})$, while the $\alpha$ value of about $0 \mathrm{~dB} / \mathrm{km}$ at room temperature remained unchanged until the temperature $(T)$ approached $T_{0}$ [4]. The $\alpha$ value increased by nearly $1,900 \mathrm{~dB} / \mathrm{km}\left(\sim 0.44 \mathrm{~m}^{-1}\right)$ at $\lambda_{0}=1.064 \mu \mathrm{m}$ when $T$ 
changed from $T_{0}$ to $T_{0}+50 \mathrm{~K}$. Furthermore, Kashyap et al. reported that the best fit between the experimental and theoretical fiber fuse velocities was obtained when the $\alpha$ value of the Ge-doped silica core at high temperatures of above $T_{0}$ was fixed to be $4.0 \times 10^{4} \mathrm{~m}^{-1}$ at 1.064 $\mu \mathrm{m}[19]$.

Hand and Russell found that this phenomenon was initiated by the generation of large numbers of Ge-related defects at high temperatures of above about 1,273 K, and the $\alpha$ values at $\lambda_{0}=0.5 \mu \mathrm{m}$ obtained at temperatures of below $1873 \mathrm{~K}$ were modeled quite accurately using an Arrhenius equation [5], [6]. By contrast, they reported that the best fit between the experimental and theoretical fiber fuse velocities was obtained when the $\alpha$ value of the Ge-doped silica core at 2,293 $\mathrm{K}$ was assumed to be $5.6 \times 10^{4} \mathrm{~m}^{-1}$ at $0.5 \mu \mathrm{m}$ [5]. This large $\alpha$ value, however, could not be estimated using their Arrhenius equation [6]. As the focal length $F$ of thermal lense effect is inversely as the $\alpha$ value [63], large $\alpha$ value of $5.6 \times 10^{4}$ $\mathrm{m}^{-1}$ is necessary to obtain small $F$ value of $10 \mu \mathrm{m}$ order, which is comparable with observed interval and/or large front size of the cavities (see Appendix).

Furthermore, Hand and Russell reported that the electrical conductivity $\sigma$ of the fiber core increased with the temperature and that the hot spot at the fiber fuse center was plasmalike [5]. Kashyap considered that the large $\alpha$ values may be attributable to an increase in the $\sigma$ value of the fiber core at high temperatures of above $T_{0}[4]$.

It is well known that silica glass is a good insulator at room temperature, and the electrical conductivity in silica glass below $1,073 \mathrm{~K}$ is due to positively charged alkali ions moving under the influence of an applied field [64], [65]. The ionic conduction in the glass is not related solely to optical absorption.

We previously investigated the optical absorption mechanism causing the increase in the $\sigma$ value and reported the relationship between $\sigma$ and $\alpha$ in silica glass at high temperatures of above $1,273 \mathrm{~K}$ [66]-[69]. It was found that the increase in loss observed at $1.064 \mu \mathrm{m}$ can be well explained by the electronic conductivity induced by the thermal ionization of a Ge-doped silica core, and it is not directly related to the absorption of Ge $E^{\prime}$ centers.

However, the calculated $\alpha$ values resulting from the electronic conductivity at $1.064 \mu \mathrm{m}$ were of $10^{2} \mathrm{~m}^{-1}$ order at $2,873 \mathrm{~K}$, about two orders smaller than the $\alpha$ values $\left(1.0-4.0 \times 10^{4} \mathrm{~m}^{-1}\right)$ reported by Kashyap et al. [4], [19]. Therefore, we need another mechanism to explain the increase in loss at high temperatures of above $2,273 \mathrm{~K}$ to account for the large $\left(10^{4} \mathrm{~m}^{-1}\right.$ order $)$ $\alpha$ values.

To satisfy this requirement, we proposed a thermochemical $\mathrm{SiO}_{x}$ production model in 2004 [68], [69]. Using this model, we theoretically estimated large $\alpha$ values of $10^{4} \mathrm{~m}^{-1}$ order as a result of $\mathrm{SiO}_{x}$ absorption at high temperatures of $2,800 \mathrm{~K}$ or above. This model was able to quantitatively explain the relation between the fiber fuse propagation velocity and the incident laser-power intensity previously reported by other research institutions.

On the other hand, since the parameters (particularly the light-absorbing parameter) used for the numerical simulation were not optimized, the shortcoming that the maximum temperature of the core center obtained by calculation became unusually high $\left(10^{5} \mathrm{~K}\right.$ order $)$ was observed.

We have improved this model by optimizing several parameters required for the numerical computation, and we proposed an improved model in 2014 [70]. 
In the first half of this chapter we describe the improved model in detail. That is, we explain the mechanism of the increased absorption in optical fibers at high temperatures due to the thermochemical production of $\mathrm{SiO}_{x}$, and estimate high-temperature $\alpha$ values at $\lambda_{0}=1.064 \mu \mathrm{m}$. Then, using these values, we theoretically study the non-steady-state thermal conduction process in a single-mode optical fiber using the explicit finite-difference technique.

Next we have analyzed the heat transfer of HAFs with $d_{h}=r_{c}$ on the basis of the improved model, and simulated the fiber fuse propagation behavior when a high optical power of 1-20 $\mathrm{W}$ at $\lambda_{0}=1.55 \mu \mathrm{m}$ is injected into an HAF. In the latter half of this chapter we describe the results of this analysis.

\section{High-temperature optical absorption in optical fibers}

\subsection{Effect of $\mathrm{SiO}_{x}$ formation on absorption}

It has been reported that, at elevated temperatures, silica glass is thermally decomposed by the reaction [71]

$$
\mathrm{SiO}_{2} \rightleftarrows \mathrm{SiO}_{x}+(x / 2) \mathrm{O}_{2} .
$$

Among the reductants of the silica generated by this pyrolysis reaction with the formula $\mathrm{SiO}_{x}$, the most thermally stable material is $\mathrm{SiO}(x=1)$.

The internal core space heated at the elevated temperature is shielded from the external conditions. Thus, with increasing temperature, the internal pressure increases and the internal volume decreases. Dianov et al. reported that the internal core temperature is about $10,000 \mathrm{~K}$ and the internal pressure is about 10,000 atmospheres at the time of fiber fuse evolution [72]. It is thought that $\mathrm{SiO}_{x}$ generated under the high-temperature and high-pressure conditions is densely packed into the internal core space because it is not allowed to expand, and it exists in a liquidlike form. For this reason, it is thought that the optical absorption spectrum of the high-density $\mathrm{SiO}_{x}$ in the core space is similar to that of solid $\mathrm{SiO}_{x}$.

Philipp reported that the optical absorption spectrum of a $\mathrm{SiO}_{x}$ film is similar to that of amorphous $\mathrm{Si}$ because of the many $\mathrm{Si}-\mathrm{Si}$ bonds in a $\mathrm{SiO}_{x}$ film, and that the absorption coefficient $\alpha_{\mathrm{SiO}}$ for $\mathrm{SiO}(x=1)$ near the threshold energy should be about one-twentieth of that for amorphous $\mathrm{Si} \alpha_{\mathrm{Si}}$ [73]. Furthermore, Philipp estimated the theoretical concentration $f_{S i}$ of $\mathrm{Si}-\left(\mathrm{Si}_{4}\right)$ when the five possible tetrahedral conformations centering on $\mathrm{Si}, \mathrm{Si}-\left(\mathrm{Si}_{4}\right)$, $\mathrm{Si}-\left(\mathrm{Si}_{3} \mathrm{O}\right), \mathrm{Si}-\left(\mathrm{Si}_{2} \mathrm{O}_{2}\right), \mathrm{Si}-\left(\mathrm{SiO}_{3}\right)$, and $\mathrm{Si}-\left(\mathrm{O}_{4}\right)$, were completely distributed at random within amorphous $\mathrm{SiO}_{x}$ [74]. The relationship between $f_{S i}$ and $x$ for $\mathrm{SiO}_{x}$ is illustrated in Figure 4. According to Figure $4, f_{S i}$ for a $\mathrm{SiO}(x=1)$ film is $6.25 \%(=1 / 16)$. This is very close to the factor by which the $\alpha$ value was reduced (about 1/20) as reported by Philipp [73].

The optical absorption near the absorption edge of a $\mathrm{SiO}_{x}$ film is dominated by that of amorphous $\mathrm{Si}$ with the $\mathrm{Si}-\left(\mathrm{Si}_{4}\right)$ tetrahedral conformation, and the optical absorption coefficient $\alpha_{\mathrm{SiO}_{x}}$ near the absorption edge of a $\mathrm{SiO}_{x}$ film can be calculated by multiplying the value of $\alpha_{S i}$ for amorphous $\mathrm{Si}$ by $f_{S i}$. That is, if the production rate of $\mathrm{SiO} x$ given by Eq. 


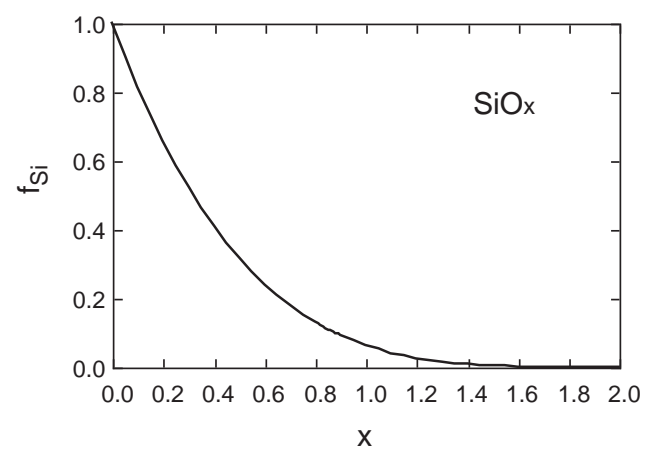

Figure 4. Relative content of $\mathrm{Si}-\left(\mathrm{Si}_{4}\right)$ in $\mathrm{SiO}_{x}$.

(1) is denoted by $g_{\mathrm{SiO}_{x}}$, then $\alpha_{\mathrm{SiO}_{x}}$ at temperature $T$ is given by

$$
\alpha_{\mathrm{SiO}_{x}}(T)=g_{\mathrm{SiO}_{x}}(T) f_{\mathrm{Si}}(x) \alpha_{\mathrm{Si}}(T)
$$

\subsection{Production rate of $\mathrm{SiO}_{x}$}

The most thermally stable compound in $\mathrm{SiO}_{x}$ generated via Eq. (1) is $\mathrm{SiO}(x=1)$. Therefore, the production rate $g_{\mathrm{SiO}_{x}}$ of $\mathrm{SiO}_{x}$ in Eq. (2) is assumed to be almost equal to the production rate $g_{\mathrm{SiO}}$ of $\mathrm{SiO}$.

$g_{\mathrm{SiO}}$ at temperature $T$ can be calculated as the ratio of the molar concentration $c_{\mathrm{SiO}}$ of $\mathrm{SiO}$ at temperature $T$ to the maximum value $c_{\mathrm{SiO}}^{0}$. This $c_{\mathrm{SiO}}^{0}$ is the molar concentration when $\mathrm{SiO}_{2}$ changes to $\mathrm{SiO}$ via Eq. (1) with a yield of about $100 \%$.

We assumed that the pyrolysis reaction system given by Eq. (1) reaches its equilibrium state during fiber fuse propagation. The equilibrium constant for Eq. (1) is denoted as $K_{c}$. The value of $c_{\mathrm{SiO}}$ at temperature $T$ was calculated using $K_{c}$ as described below.

First, the initial molar concentration $c_{\mathrm{SiO}_{2}}^{s}\left(=0.0366 \mathrm{~mol} \mathrm{~cm}{ }^{-3}\right)$ is denoted by $a$. We consider the case that the $\mathrm{SiO}_{2}$ concentration decreases to $a-y$ via the pyrolysis reaction of Eq. (1). In this case, the molar concentration of $\mathrm{SiO}$ and the molar concentration $c_{\mathrm{O}_{2}}$ of $\mathrm{O}_{2}$ are expressed as $y$ and $y / 2$, respectively. $K_{c}$ is given in terms of $a$ and $y$ as follows:

$$
K_{c}=\frac{{ }^{c} \mathrm{SiO}{ }^{1 / 2} \mathrm{O}_{2}}{{ }^{c} \mathrm{SiO}_{2}}=\frac{y(y / 2)^{1 / 2}}{a-y} .
$$

Rearranging Eq. (3), we obtain a cubic equation in $y$. The solution of this equation is given by

$$
y=\sqrt[3]{C}+\frac{4 K_{c}^{2}}{3 \sqrt[3]{C}}\left(\frac{K_{c}^{2}}{3}-a\right)+\frac{2 K_{c}^{2}}{3},
$$


where

$$
\begin{aligned}
C & =a^{2} K_{c}^{2}-\frac{4}{3} a K_{c}^{4}+\frac{8}{27} K_{c}^{6} \\
& +a^{2} K_{c}^{2} \sqrt{1-\frac{8 K_{c}^{2}}{27 a}} .
\end{aligned}
$$

It is well known that the equilibrium constant $K_{c}$ is related to the standard Gibbs energy change $\Delta_{r} G^{0}$ for Eq. (1). The relationship between $K_{c}$ and $\Delta_{r} G^{0}$ is given by [75]

$$
\ln K_{c}=\frac{-\Delta_{r} G^{0}}{R T}
$$

where $R$ is the gas constant. The $\Delta_{r} G^{0}$ value for Eq. (1) is given by

$$
\begin{aligned}
\Delta_{r} G^{0} & =\Delta_{f} G_{\mathrm{SiO}}^{0}+(1 / 2) \Delta_{f} G_{\mathrm{O}_{2}}^{0} \\
& -\Delta_{f} G_{\mathrm{SiO}_{2}}^{0}
\end{aligned}
$$

where $\Delta_{f} G^{0}$ is the standard production Gibbs energy of a reactant and/or a product.

Vitreous silica $\left(\mathrm{SiO}_{2}\right)$ is a solid at the standard temperature $(298.15 \mathrm{~K})$. It melts at high temeperatures of above $1,996 \mathrm{~K}$, and becomes a liquid. It also becomes a vapor at temperatures of above 3,000 K.

The standard production Gibbs energies $\Delta_{f} G_{\mathrm{SiO}_{2}}^{0} \Delta_{f} G_{\mathrm{SiO}^{\prime}}^{0}$ and $\Delta_{f} G_{\mathrm{O}_{2}}^{0}$ in each phase have been published [76]. Thus, using these $\Delta_{f} G^{0}$ values, we first calculated the standard Gibbs energy change $\Delta_{r} G^{0}$ for Eq. (1). Next, we calculated $K_{c}$ by substituting the $\Delta_{r} G^{0}$ value into Eq. (6). In this way, we computed $c_{\mathrm{SiO}}(=y)$ at temperature $T$ by substituting $K_{c}$ and $a(=$ $0.0366 \mathrm{~mol} \mathrm{~cm}^{-3}$ ) into Eqs. (4) and (5). The relationship between $c_{\mathrm{SiO}}$ and $T$ is shown in Figure 5. $c_{\mathrm{SiO}}$ increases with increasing $T$ and gradually approaches its maximum value $\left(c_{\mathrm{SiO}}^{0} \cong 0.0366 \mathrm{~mol} \mathrm{~cm}^{-3}\right)$ at $T$ of about $3,200 \mathrm{~K}$.

Therefore, $g_{\mathrm{SiO}_{x}}$ at temperature $T$ was estimated by dividing the value of $c_{\mathrm{SiO}}$ calculated above by $c_{\mathrm{SiO}}^{0}\left(\cong 0.0366 \mathrm{~mol} \mathrm{~cm} \mathrm{~cm}^{-3}\right)$.

\subsection{Absorption coefficient of amorphous $\mathrm{Si}$}

The optical absorption spectrum of amorphous Si was reported by Brodsky et al. [77]. The absorption coefficient $\alpha_{\mathrm{Si}}$ of amorphous Si in Eq. (2) was estimated as follows. 


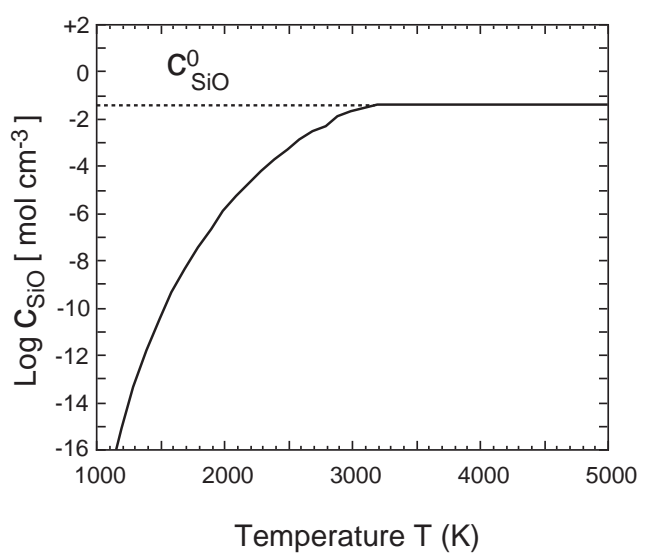

Figure 5. Molar concentration of SiO vs. temperature.

First, we consider the absorption coefficient $\alpha_{\mathrm{Si}}$ of an interband transition region, where the photon energy $\hbar \omega$ is larger than the energy gap $E_{g}(=1.26 \mathrm{eV})$ of amorphous $\mathrm{Si}$. In this case, the values of $\alpha_{\mathrm{Si}}\left(\mathrm{cm}^{-1}\right.$ unit) near $E_{g}$ is given by

$$
\alpha_{\mathrm{Si}}(\omega)=B \frac{\left(\hbar \omega-E_{g}\right)^{2}}{\hbar \omega}
$$

where the parameter $B$ is $5.06 \times 10^{5} \mathrm{~cm}^{-1} \mathrm{eV}^{-1}$. The $\alpha_{\mathrm{Si}}$ values calculated by Eq. (8) are in good agreement with the experimental values reported by Brodsky et al. [77] for the case of $\hbar \omega>1.5 \mathrm{eV}$.

Next, we consider the values of $\alpha_{S i}$ in the low-energy region, where $\hbar \omega<E_{g}$. In this region, an absorption edge spectrum is broadened as a result of the interaction between optical phonons and electrons (or excitons). $\alpha_{\mathrm{Si}}$ in this region exhibits exponential behavior (referred to as an"exponential tail" or "Urbach tail") as follows [78]:

$$
\alpha_{\mathrm{Si}}(\omega)=\alpha_{0} \exp \left[\frac{\gamma\left(\hbar \omega-E_{g}\right)}{k T^{*}}\right]
$$

where $\alpha_{0}$ and $\gamma$ are parameters and $k$ is the Boltzmann constant. $T^{*}$ is the effective temperature. If the characteristic temperature of phonons is denoted by $\theta$, then $T^{*}$ is given by [79]

$$
T^{*}=\frac{\theta}{2} \operatorname{coth}\left(\frac{\theta}{2 T}\right) .
$$

For $\mathrm{Si}, \theta=600 \mathrm{~K}$ [80]. $\alpha_{0}$ and $\gamma$ are estimated to be $9.016 \times 10^{3} \mathrm{~cm}^{-1}$ and 0.14 , respectively, by simulation using the experimental $\alpha_{\mathrm{Si}}$ values reported by Brodsky et al. [77]. 
It is known that the energy gap $E_{g}$ of $\mathrm{Si}$ decreases linearly with increasing $T$ at $T>200 \mathrm{~K}$ [81]. The temperature dependence of $E_{g}$ (eV unit) at $T>300 \mathrm{~K}$ is given by

$$
E_{g}=1.26-\beta T,
$$

where $\beta$ is the temperature coefficient of the energy gap and takes a value of $4.2 \times 10^{-4}$ $\mathrm{eV} / \mathrm{K}[82]$.

\subsection{Absorption coefficient of $\mathrm{SiO}_{x}$}

On the basis of the above results, the temperature dependence of $\alpha_{\mathrm{SiO}_{x}}$ at $1.064 \mu \mathrm{m}(\hbar \omega=$ $1.17 \mathrm{eV}$ ) was calculated using Eq. (2) and the $c_{\mathrm{SiO}}$ values shown in Figure $5 . f_{\mathrm{Si}}=0.0625$ ( $x$ $=1$ ) was used in the calculation. The results are shown in Figure 6.

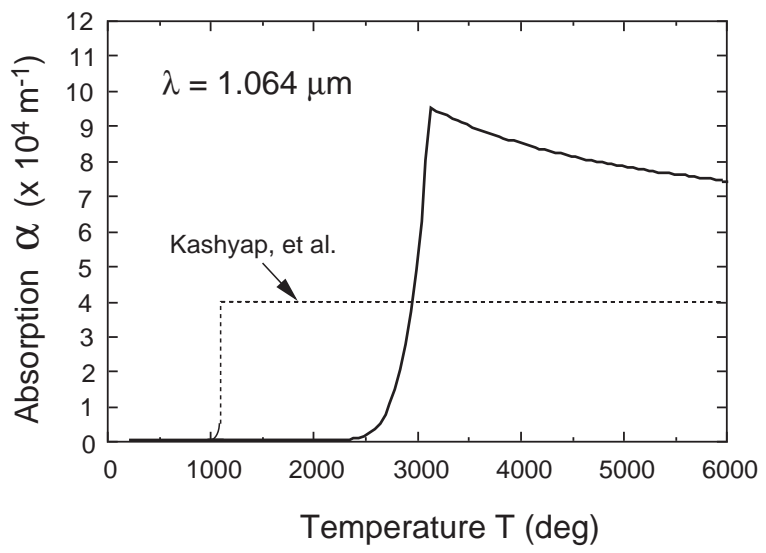

Figure 6. Absorption coefficient of $\mathrm{SiO}_{x}$ at $1.064 \mu \mathrm{m}$ vs. temperature. The thick solid line was calculated using Eq. (2). The dotted line shows the values estimated by Kashyap et al.

The $\alpha_{\mathrm{SiO}_{x}}$ values (shown as the thick solid line in Figure 6) are about $1.5 \times 10^{4} \mathrm{~m}^{-1}$ at 2,800 $\mathrm{K}$ and about $3.5 \times 10^{4} \mathrm{~m}^{-1}$ at $2,950 \mathrm{~K}$. These values are close to $4 \times 10^{4} \mathrm{~m}^{-1}$ (shown as the dotted line in Figure 6), which was estimated by simulation using the finite element method [19].

Moreover, it turns out that $\alpha_{\mathrm{SiO}_{x}}$ reaches its maxium value (about $9.47 \times 10^{4} \mathrm{~m}^{-1}$ ) at about $3,150 \mathrm{~K}$, then decreases gradually with increasing temperature.

Compared with the stepwise shape (dotted line in Figure 6) of the absorption coefficient assumed by Kashyap et al., the maximum value (about $9.47 \times 10^{4} \mathrm{~m}^{-1}$ ) of $\alpha_{\mathrm{SiO}_{x}}$ is about 2.4 times the assumed value $\left(4 \times 10^{4} \mathrm{~m}^{-1}\right)$, and the graph has the shape of a somewhat distorted echelon form.

As mentioned above, $\mathrm{SiO}_{x}$ is produced in the pyrolysis of vitreous silica, and it induces a very large amount of optical absorption with a large absorption coefficient of $10^{4} \mathrm{~m}^{-1}$ order at 
high temperatures of above $2,800 \mathrm{~K}$. It is thought that the large amount of optical absorption at high temperatures is the cause of the genesis of the fiber fuse phenomenon.

We investigated the thermal conduction behavior within an SMF by numerical computation using the thermochemical $\mathrm{SiO}_{x}$ production model. In the next section, we describe the results of some numerical calculations related to the thermal conduction process in an SMF.

\section{Simulation of fiber fuse in SMF}

\subsection{Heat conduction in SMF}

We assume the SMF to have a radius of $r_{f}$ and to be in an atmosphere with temperature $T$ $=T_{a}$. We also assume that part of the core layer of length $\Delta L$ is heated to a temperature of $T_{c}^{0}\left(>T_{a}\right)$ (see Figure 7). Such a region, called the "hot zone" in Figure 7, can be generated by heating the fiber end faces using the arc discharge of a fusion splice machine.

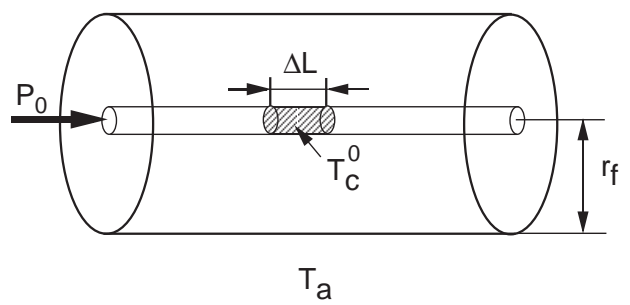

Figure 7. Hot zone in the core layer.

As explained above, the optical absorption coefficient $\alpha$ of the core layer in an optical fiber is a function of temperature $T$, and $\alpha$ increases with increasing $T$. In the hot zone in Figure 7 , the $\alpha$ values are larger than those in the remainder of the core region because of its elevated temperature. Thus, as light propagates along the positive direction (away from the light source) in this zone, considerable heat is produced by light absorption.

In the case of a heat source in part of the core layer, the nonsteady heat conduction equation for the temperature field $T(r, z, t)$ in the SMF is given by [83]

$$
\begin{aligned}
\rho C_{p} \frac{\partial T}{\partial t} & =\lambda\left(\frac{\partial^{2} T}{\partial r^{2}}+\frac{1}{r} \frac{\partial T}{\partial r}+\frac{\partial^{2} T}{\partial z^{2}}\right) \\
& +\dot{Q}
\end{aligned}
$$

where $\rho, C_{p}$, and $\lambda$ are the density, specific heat, and thermal conductivity of the fiber, respectively. The values of $\rho, C_{p}$, and $\lambda$ used for the calculation are described in the next subsection.

The last term $\dot{Q}$ in Eq. (12) represents the heat source resulting from light absorption, which is only required for the hot zone in the fiber core. $\dot{Q}$ can be expressed by 


$$
\dot{Q}=\alpha I,
$$

where $I$ is the optical power intensity in the core layer, which can be estimated by dividing the incident optical power $P$ by the effective area $A_{e f f}$ of the fiber.

\subsection{Heat conduction parameters}

In the heat conduction calculation for SMFs, we used the following values of $\lambda\left(\mathrm{W} \mathrm{m}^{-1} \mathrm{~K}^{-1}\right)$, $\rho\left(\mathrm{kg} \mathrm{m}^{-3}\right)$, and $C_{p}\left(\mathrm{~J} \mathrm{~kg}^{-1} \mathrm{~K}^{-1}\right)$ in each temperature range. The unit of $T$ is $\mathrm{K}$ (Kelvin).

(1) Parameters in the temperature range from room temperature (298 K) to 1,996 K [84]:

$$
\begin{aligned}
C_{p}= & 1194.564+31.541 \times 10^{-3} \mathrm{~T} \\
& -651.396 \times 10^{5} \mathrm{~T}^{-2} \\
\lambda= & 9.2 \\
\rho= & 2,200.0 .
\end{aligned}
$$

(2) Parameters in the temperature range from 1,996 to 3,000 K [84]:

$$
\begin{aligned}
C_{p} & =1,430.490 \\
\lambda & =9.2 \\
\rho & =2,200.0 .
\end{aligned}
$$

(3) Parameters for $T>3,000 \mathrm{~K}$ :

$$
\begin{aligned}
C_{p}= & 844.4 \\
\lambda= & 0.0025247 \sqrt{T} \\
& +1.84275 \times 10^{-13} T^{5 / 2} \\
\rho= & 2,024.0 .
\end{aligned}
$$

In (3), the first term in the expression for $\lambda$ was estimated by substituting the parameters for $\mathrm{SiO}$ in the following equation, which represents the thermal conductivity of diatomic molecules derived from the kinetic theory of gases [85]:

$$
\lambda=\frac{5}{3 \sigma^{2}} \sqrt{\left(\frac{k}{\pi}\right)^{3} \frac{N_{A}}{M}} \sqrt{T},
$$

where $N_{A}$ is Avogadro's number, $M(=44.0854)$ is the molecular weight of $\mathrm{SiO}$, and $\sigma(=1.5$ $\AA$ ) is half of the collision diameter. 
Moreover, in (3), the second term in the expression for $\lambda$ was estimated by mutiplying the following thermal conductivity equation for weakly ionized gas plasma [86] by the correction factor of $1 / 20$ :

$$
\lambda=\frac{5 N_{e} k^{2} T}{2 m_{e} v_{c}}
$$

where $m_{e}$ is the electron mass, $N_{e}$ is the number density of electrons in the plasma, and $v_{\mathcal{C}}$ is the collision frequency. If we assume that electrons mainly collide with ions with a charge of +1 in the plasma, then $v_{c}$ is given by [87]

$$
v_{c}=\sqrt{\frac{2}{9 \pi}} \frac{N_{e} e^{4}}{\varepsilon_{0}^{2} m_{f e}^{2}}\left(\frac{m_{e}}{3 k T}\right)^{3 / 2} \ln \Lambda,
$$

where $e$ is the electron charge and $\varepsilon_{0}$ is the permittivity of free space. $\ln \Lambda$ is the so-called Coulomb logarithm, and it takes values of 4-34 in the electron temperature range of $10^{2}-10^{8}$ $\mathrm{K}$ and the $N_{e}$ range of $1-10^{24} \mathrm{~cm}^{-3}$ [88]. In our calculation, we used $\ln \Lambda=16.155$, which corresponds to the case of $T \sim 10^{4} \mathrm{~K}$ and $N_{e} \sim 10^{6} \mathrm{~cm}^{-3}$.

\subsection{Boundary and initial conditions for heat conduction}

We solved Eq. (12) using the explicit finite-difference method (FDM) [89] under the boundary and initial conditions described below.

The area in the numerical calculation had a length of $2 L(=4 \mathrm{~cm})$ in the axial $(z)$ direction and a width of $2 r_{f}(=125 \mu \mathrm{m})$ in the radial $(r)$ direction. There were 24 and 2,000 divisions in the $r$ and $z$ directions, respectively, and we set the calculation time interval to $1 \mu \mathrm{s}$. We assumed that the hot zone was located at the center of the fiber (length $2 L$ ) and that the length $\Delta L$ of the hot zone was $40 \mu \mathrm{m}$.

The boundary conditions are as follows:

(1) Since the temperature distribution of the optical fiber is axisymmetric, the amount of heat conducted per unit area (heat flux) in the $r$ direction is set to 0 at the fiber center $(r=0)$ as follows:

$$
-\left.\lambda \frac{\partial T}{\partial r}\right|_{r=0}=0
$$

(2) At the outer fiber surface $\left(r=r_{f}\right)$, the amount of heat conducted per unit area (heat flux) is dissipated by radiative transfer or heat transfer to the open air and/or the jacketing layer $\left(T=T_{a}\right)$ as follows:

$$
\begin{aligned}
-\left.\lambda \frac{\partial T}{\partial r}\right|_{r=r_{f}} & =\sigma_{S} \epsilon_{e}\left(T^{4}-T_{a}^{4}\right) \\
& +\frac{\lambda}{\delta r_{t}}\left(T-T_{a}\right)
\end{aligned}
$$


where $\sigma_{S}$ is the Stefan-Boltzmann constant and $\epsilon_{e}(\sim 0.9)$ is the emissivity of the surface. $\delta r_{t}$ is the thickness of the thermal boundary layer and $\delta r_{t}=\delta r$ is assumed in our calculation, where $\delta r$ is the step size along the $r$ axis.

(3) At the center $(z=0)$ of the hot zone, the temperature of the fiber core center is $T_{c}^{0}$. Also, there is heat inflow along the $z$ axis only at the core center $(r=0)$, which is attributable to light absorption. Moreover, when $r \neq 0$ and $z=0$, there is neither heat inflow nor heat outflow along the $z$ axis. These conditions are given by

$$
-\left.\lambda \frac{\partial T}{\partial z}\right|_{z=0}= \begin{cases}\alpha I, & \text { if } r=0 \\ 0 & \text { if } r \neq 0\end{cases}
$$

(4) At both fiber ends $(z= \pm L)$, the amount of heat conducted per unit area (heat flux) is dissipated by radiation transfer to the open air $\left(T=T_{a}\right)$ as follows:

$$
-\left.\lambda \frac{\partial T}{\partial z}\right|_{z= \pm L}=\sigma_{S} \epsilon_{e}\left(T^{4}-T_{a}^{4}\right)
$$

In contrast, as initial conditions, $T=T_{a}$ in the optical fiber at $t=0$, except in the hot zone, and the core-center temperature in the hot zone is equal to $T_{\mathcal{c}}^{0}\left(>T_{a}\right)$ as follows:

$$
T(0, z, 0)= \begin{cases}T_{a}, & \text { if }-L \leq z<-\Delta L / 2 \\ T_{c}^{0}, & \text { if }-\Delta L / 2 \leq z \leq \Delta L / 2 \\ T_{a} & \text { if } \Delta L / 2<z \leq L\end{cases}
$$

When light propagates through the fiber core $(r=0)$ along the $z$ direction (away from the light source), the incident laser power $P$ decreases because of the nonzero optical absorption coefficient $\alpha$. When the laser light propagates from $z$ to $z+\delta z$ along the $z$ axis at $r=0$, the $P$ value is given by

$$
P=P_{0} \exp \left(-\alpha \delta z-\int_{-L}^{z} \alpha(T) d z\right),
$$

where $P_{0}$ is the initial laser power. The second term on the right-hand side expresses the optical absorption loss when the light propagates through a distance of $z-L$.

The results described above assume that the laser light propagates through the fiber core along the positive $z$ direction (away from the light source).

When the core layer is heated to above the vaporization point of silica $(\sim 3273 \mathrm{~K})$, an enclosed hollow cavity is produced in the core center. This cavity contains oxygen, which is produced by the pyrolysis reaction of Eq. (1). The heat conductivity $\kappa$ of the oxygen $\left(0.03 \mathrm{~W} \mathrm{~m}^{-1} \mathrm{~K}^{-1}\right)$ is two orders smaller than that of the silicate glass. Therefore, the heat transferred in the silica core is stopped at the cavity. 
Moreover, as the cavity has a refractive index of $n \sim 1$, which is smaller than that of the silica core $\left(n_{1}=1.46\right)$, the light propagating in the core layer is reflected at the cavity wall. When the light direction is reversed at the cavity, the heat source term $\alpha I_{r}$ resulting from the optical absorption of the reflected light is added to $\alpha I$ in Eq. (13), where $I_{r}$ is the optical power intensity of the reflected laser light.

We consider the $P$ value at a $z$ position located near the cavity wall. The length of this position is assumed to be $\delta z$. The laser light reaches $z$, propagates through a distance of $\delta z$, and then reaches the cavity wall, whose coordinate is $z_{v}$. Next, the light is reflected at the cavity wall and propagates in the negative $z$ direction, and then reaches $z$ again. In such a case, the $P$ value at $z$ is given by

$$
\begin{aligned}
P & =P_{0} \exp \left(-\alpha \delta z-\int_{-L}^{z} \alpha(T) d z\right) \\
& \times R \exp \left(-2 \int_{z+\delta z}^{z_{v}} \alpha(T) d z\right),
\end{aligned}
$$

where $R$ is the reflectivity at the boundary of the silica core and the cavity. $R$ is given by

$$
R=\left(\frac{n_{1}-1}{n_{1}+1}\right)^{2}
$$

The second integral on the right-hand side of Eq. (23), which is related to the reflected light, slightly affects the occurrence of the fiber fuse. However, by taking this term into consideration, the calculated fiber fuse velocities fit the experimental values. For this reason, in the present work, we decided to take into account the effect of the reflected light.

In the following section, we describe the calculated time $(t)$ dependence of $T(r, z)$ in an SMF.

\subsection{Propagation of fiber fuse in SMF}

In the calculation, we used $T_{c}^{0}=2923 \mathrm{~K}$ and $T_{a}=298 \mathrm{~K}$. It was assumed that laser light of wavelength $\lambda_{0}=1.064 \mu \mathrm{m}$ and $P_{0}=2 \mathrm{~W}$ was incident to an SMF-28 optical fiber, which has a core diameter of $2 r_{c}=8.2 \mu \mathrm{m}$, a refractive index difference of $\Delta=0.36 \%$, and $A_{e f f}=49.4091$ $\times 10^{-12} \mathrm{~m}^{2}$.

We calculated the $T(r, z)$ values at $t=1,11$, and $21 \mathrm{~ms}$ after the incidence of the $2 \mathrm{~W}$ laser light. The calculated results are shown in Figures $8 \sim 10$, respectively.

As shown in Figure 8, the core center temperature near the end of the hot zone $(z=-0.7$ $\mathrm{mm}$ ) changes abruptly to a large value of about $3.4 \times 10^{4} \mathrm{~K}$ after $1 \mathrm{~ms}$. This rapid rise in the temperature initiates the fiber fuse phenomenon as shown in Figures 9 and 10. After 11 and $21 \mathrm{~ms}$, the high-temperature front in the core layer reached $z$ values of -6.1 and $-11.5 \mathrm{~mm}$, respectively. The average propagation velocity $v_{f}$ was estimated to be $0.54 \mathrm{~m} / \mathrm{s}$ using these data. 
$\mathrm{T}\left(\times 10^{3} \mathrm{~K}\right)$

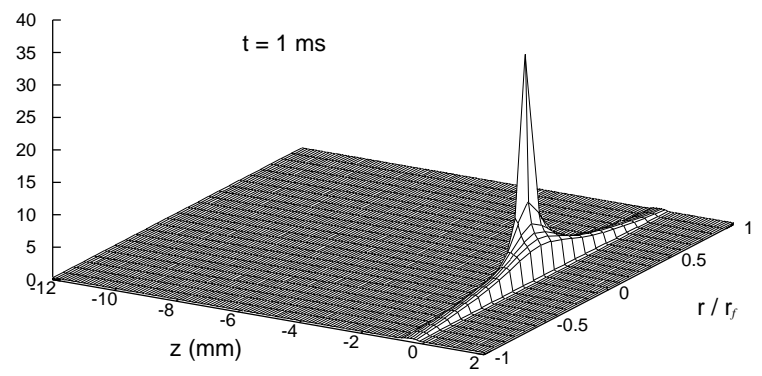

Figure 8. Temperature field in SMF-28 after $1 \mathrm{~ms}$ when $P_{0}=2 \mathrm{~W}$ at $\lambda_{0}=1.064 \mu \mathrm{m}$.

$\mathrm{T}\left(\times 10^{3} \mathrm{~K}\right)$

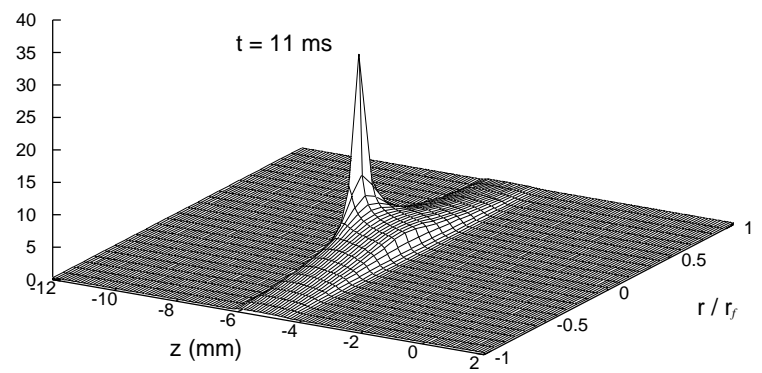

Figure 9. Temperature field in SMF-28 after $11 \mathrm{~ms}$ when $P_{0}=2 \mathrm{~W}$ at $\lambda_{0}=1.064 \mu \mathrm{m}$.

\section{$\mathrm{T}\left(\times 10^{3} \mathrm{~K}\right)$}

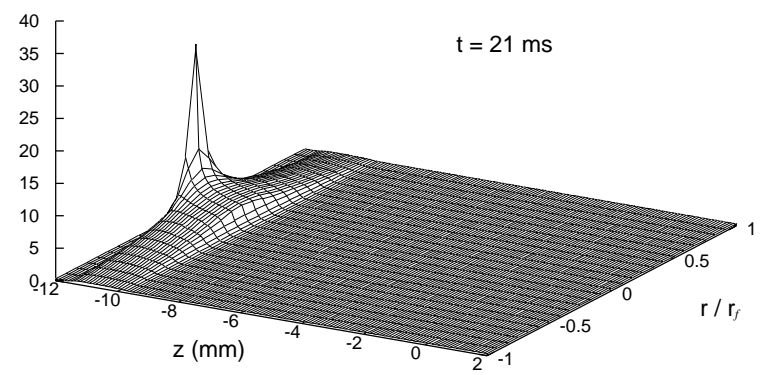

Figure 10. Temperature field in SMF-28 after $21 \mathrm{~ms}$ when $P_{0}=2 \mathrm{~W}$ at $\lambda_{0}=1.064 \mu \mathrm{m}$. 
When the laser light of $\lambda_{0}=1.064 \mu \mathrm{m}$ and $P_{0}=2 \mathrm{~W}$ is incident to the SMF-28 optical fiber, the optical power intensity is $I=4.048 \mathrm{MW} / \mathrm{cm}^{2}$. The fiber fuse velocity at this value of $I$ is estimated to be about $0.55 \mathrm{~m} / \mathrm{s}$ (see Figure 10 in [69]). This value is in very good agreement with the upper value obtained by calculation $(0.54 \mathrm{~m} / \mathrm{s})$.

On the other hand, Hand and Russell measured the fiber fuse temperature to be 5,400 K [5], and Dianov et al. obtained a temperature of 4,700-10,500 K [28],[90] by measurement. They estimated the temperatures from precisely measured spectral data in the $600-1,400 \mathrm{~nm}$ [5] and 500-800 $\mathrm{nm}$ [28],[90] regions, while assuming blackbody radiation.

In our calculation, the temperature distribution of the fiber fuse in the core center is shown in Figure 11. Similar shapes of temperature distribution were reported by Kashyap et al. [19]

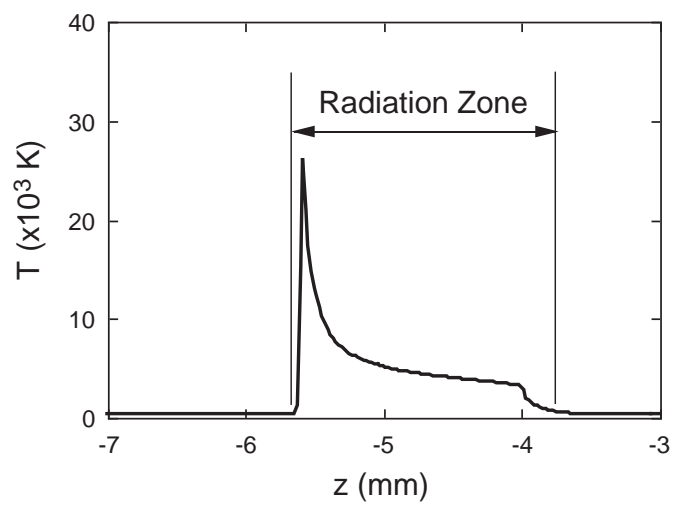

Figure 11. Temperature distribution of the SMF-28 core center vs. length along the $z$ direction when $P_{0}=2 \mathrm{~W}$ at $\lambda_{0}=1.064$ $\mu \mathrm{m}$. The time after the laser incidence is $10 \mathrm{~ms}$.

and Facão et al. [56].

As shown in Figure 11, it is clear that the sharp temperature peak is located near the light source, and a relatively high temperature plateau of about 5,000 K extends over about 1.5 mm behind the sharp peak. This region, called the "radiation zone" in Figure 11, exhibits high temperatures of above $323 \mathrm{~K}$.

When gaseous $\mathrm{SiO}$ and/or $\mathrm{SiO}_{2}$ molecules are heated to high temperatures above 5,000 K, they decompose to form $\mathrm{Si}$ and $\mathrm{O}$ atoms, and finally becomes $\mathrm{Si}^{+}$and $\mathrm{O}^{+}$ions and electrons in the ionized gas plasma state [91]. The numbers of electrons and ions in the plasma front, which exhibits sharp temperature peak, are larger than those in the plateau region. However, as the plasma tends to restore electrical neutrality, the motions of the electrons and ions will not produce any change on the initial temperature distribution shown in Figure 11, except for the peak temperature reduction of the plasma front due to energy loss induced by electron-ion collisions.

In the ionized gas plasma, electron-ion collisions generate electromagnatic radiation because of the deceleration during the collisions. This bremsstrahlung emission [92], [93] is a universal and irreducible process of energy loss. If we assume that electrons mainly collide 
with ions with a charge of +1 in the plasma, the spectral radiance function $I_{p}$ for the bremsstrahlung emission is given by [94]

$$
I_{p}=\frac{N_{e}^{2} v^{2}}{\sqrt{T} c^{2}} \exp \left(-\frac{h v}{k T}\right)
$$

where $N_{e}$ is the number density of electrons in the plasma, $h$ is Planck's constant, and $v$ is the optical frequency. This functin is directly proportionate to $v^{2}$ in the case of $h v \ll k T$.

On the other hand, in the case of $h v \ll k T$, the spectral radiance function $I_{b}$ for blackbody radiation is given by [95]

$$
I_{b}=\frac{2 \pi v^{2}}{c^{2}} k T \text {. }
$$

This is well-known as the Rayleigh-Jeans formula, and this function is proportional to $v^{2}$, too. Therefore, we assumed that the radiation zone, in which the bremsstrahlung emission of the plasma is liberated, can be treated as a blackbody because of its similar dependence on $v$.

If we consider the radiation zone as a blackbody, that is isolated from the surrounding nonheated regions, it is expected that the radiation zone will exhibit a radiation spectrum with a broad range of optical frequencies ranging from ultraviolet to infrared. The blackbody temerature $T_{b}$ of the zone is related to the frequency $v_{m}$ of the spectral peak as follows [95]:

$$
v_{m}=\frac{2.82 k T_{b}}{h}
$$

If $T_{a v}$ is defined as the average temperature of the radiation zone, the $T_{b}$ will be close to the $T_{a v}$.

The relationship between the $T_{a v}$ value and the time after fiber fuse generation is shown in Figure 12. $T_{a v}$ exceeds $10000 \mathrm{~K}$ immediately after fiber fuse generation but is less than 7000 $\mathrm{K}$ after $4 \mathrm{~ms}$. Then it gradually approaches about 5,700 K. The value of 5,760 K shown in Figure 12 is the average $T_{a v}$ value from 4 to $30 \mathrm{~ms}$. This temperature $(5,760 \mathrm{~K})$ is close to the reported temperatures of 5,400 K [5] and about 5,800 K [90].

Thus, it was found that if a fiber fuse, which exhibits a sharp temperature peak located near the light source, is approximated as a blackbody isolated from the surrounding nonheated regions, its average temperature from $4 \mathrm{~ms}$ after the generation of the fiber fuse approaches the experimentally estimated radiation temperatures.

\section{Modeling of Hole-Assisted Fiber}

In a Hole-Assisted Fiber (HAF), some holes exist around the main core as shown in Figure 1. In this HAF, the minimum distance of the holes from the main core is only $\left(D_{\text {hole }}-2 r_{c}\right) / 2$. These holes are filled with air at the same temperature as the surrounding air $\left(T_{a}\right)$. Therefore, at the inner surfaces of the holes, it can be expected that heat transfer or radiative transfer 


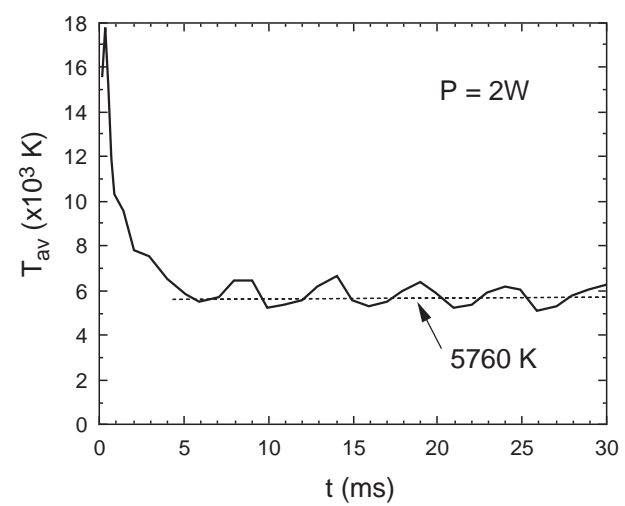

Figure 12. Average temperature of radiation zone vs. time after fiber fuse generation.

will occur between the heated solid inner surfaces of the holes and the gaseous fluid (air) with the low temperature of $T=T_{a}$. This is expected to affect the heat conduction behavior in the core center of the HAF.

Thus, we used the model proposed by Takara et al. [44] for heat conduction analysis, which includes heat transfer or radiative transfer between the inner surfaces of the holes and the gaseous air in the HAF. The proposed model for the HAF is shown in Figure 13.
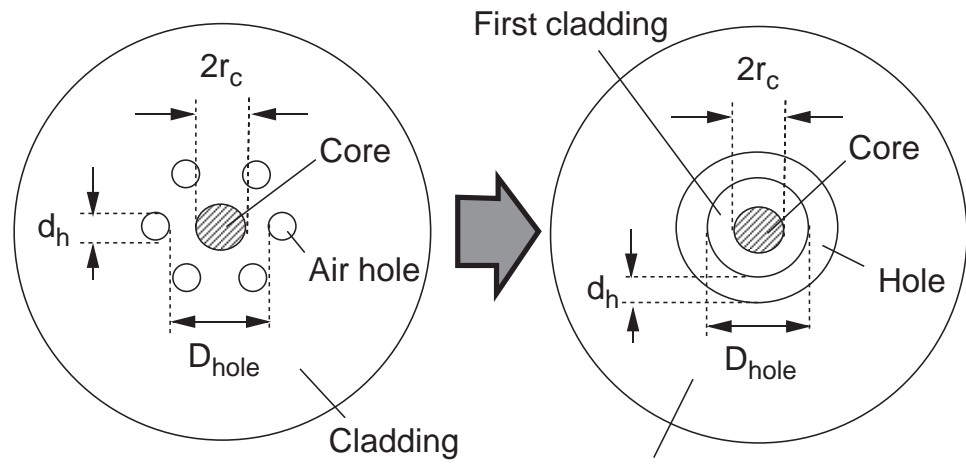

Second cladding

Figure 13. Heat conduction model of HAF [44].

Although bridges of silica glass exist between the holes in an actual HAF, to simplify the calculation, the first cladding layer was assumed to be a cylindrical layer of $D_{\text {hole }}$ diameter, and the hole layer was treated as a gap of $d_{h}$ width, which was inserted between the first and second cladding layers (see Figure 13). The hole layer was assumed to be fulfilled with a silica-air mixture. In the hole layer, the volume ratio of a silica glass to an air was $(1-\gamma)$ $: \gamma$, where $\gamma_{1}$ is the occupancy of the 6-air holes in the cross section of HAF. Furthermore, 
it was assumed that heat transfer and radiative transfer occurred at the inner surface of the hole layer in addition to heat conduction between the silica glass and the silica-air mixture.

When a certain quantity of heat per unit area (heat flux) is conducted from the heated core center to the end of the first cladding layer $\left(r=D_{\text {hole }} / 2\right)$ of an optical fiber, a considerable amount of the heat flux is transmitted through the hole layer, and the residual heat flux stagnates in the first cladding layer because the thermal conductivity $\kappa$ of the hole layer is lower than that of silica glass.

This heat flux stagnating in the first cladding layer can be dissipated by radiative transfer and heat transfer between the outer surface of the first cladding layer and the air in the hole layer with a temperature of $T_{a}$.

It is noteworthy here that the total surface area of the 6-air holes existing in an actual HAF is larger than the outer surface area of the first cladding layer when $R_{h}=2$ (see Table 1).

The heat transfer results from the convection of air, which is generated by warming the air near the outer surface of the first cladding layer. In this heat transfer, there is a region (called the "thermal boundary layer") near the surface of the first cladding layer where the temperature of the air changes rapidly from a high value to $T_{a}$.

\section{Heat conduction modeling of HAF}

We assume the HAF to have a radius of $r_{f}$ and to be in an atmosphere with temperature $T$ $=T_{a}$. We also assume that part of the core layer of $\Delta L$ length is heated to a temperature of $T_{c}^{0}\left(>T_{a}\right)$ (see Figure 14).

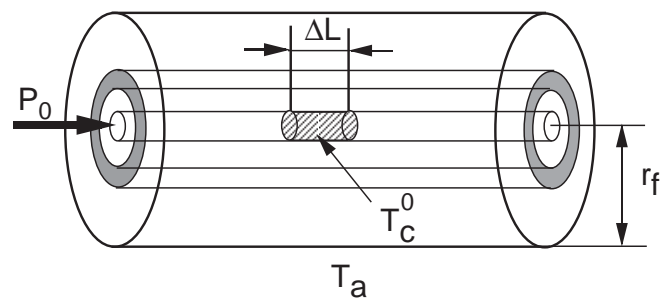

Figure 14. Hot zone in core layer of HAF.

The optical absorption coefficient $\alpha$ of the core layer in a HAF is a function of temperature $(T)$, and it increases with increasing $T$ [70]. In the heating zone (called the "hot zone") shown in Figure 14, $\alpha$ is larger than in other parts of the core because of its high temperature $T_{c}^{0}\left(>T_{a}\right)$. Thus, as light propagates along the positive direction (away from the light source) in this zone, considerable amount of heat is produced by light absorption.

In the case of a heat source in part of the core layer, the nonsteady heat conduction equation for the temperature field $T(r, z, t)$ in the HAF is given by Eq. (12). We can solve Eq. (12) using the explicit finite-difference method (FDM) under the boundary and initial conditions, described in section 3.3, and the additional boundary conditions as follows: 
(1) At the outer surface $\left(r=D_{\text {hole }} / 2\right)$ of the first cladding layer, the amount of heat conducted per unit area (heat flux) is dissipated by radiative transfer or heat transfer to the air $\left(T=T_{a}\right)$ in the hole layer as follows:

$$
\begin{aligned}
-\left.\lambda \frac{\partial T}{\partial r}\right|_{r=D_{\text {hole }} / 2} & =\gamma_{1} \sigma_{S} \epsilon_{e}\left(T^{4}-T_{a}^{4}\right) \\
& +\gamma_{1} \frac{\lambda}{\delta r_{t}}\left(T-T_{a}\right)
\end{aligned}
$$

where $\gamma_{1}$ is the ratio of the total surface area of the 6-air holes existing in an actual HAF to the outer surface area of the first cladding layer, $\delta r_{t}$ is the thickness of the thermal boundary layer, and $\delta r_{t}=x \delta r$ is assumed in the HAF calculation, where $x=0.5$.

(2) At the inner surface $\left(r=D_{\text {hole }} / 2+d_{h}\right)$ of the second cladding layer, the amount of heat conducted per unit area (heat flux) is dissipated by radiative transfer or heat transfer to the air $\left(T=T_{a}\right)$ in the hole layer as follows:

$$
\begin{aligned}
-\left.\lambda \frac{\partial T}{\partial r}\right|_{r=D_{h o l e} / 2+d_{h}} & =\gamma_{2} \sigma_{S} \epsilon_{e}\left(T^{4}-T_{a}^{4}\right) \\
& +\gamma_{2} \frac{\lambda}{\delta r_{t}}\left(T-T_{a}\right),
\end{aligned}
$$

where $\gamma_{2}$ is the ratio of the total surface area of the 6-air holes existing in an actual HAF to the inner surface area of the second cladding layer.

The fiber parameters of the HAFs used for calculation were $d_{h}=r_{c}=4.5 \mu \mathrm{m}$, which were used in the experiments reported by Hanzawa et al. [45]. $R_{h}$ was set to 2,3 , and 4 . In the following, HAFs with $R_{h}=2,3$, and 4 are called HAF2, HAF3, and HAF4, respectively.

The parameters $\gamma, \gamma_{1}, \gamma_{2}$ for HAF2, HAF3, HAF4 are shown in Table 1.

\begin{tabular}{cccc}
\hline Type & $\gamma$ & $\gamma_{1}$ & $\gamma_{2}$ \\
\hline HAF2 & 0.300 & 1.50 & 1.00 \\
HAF3 & 0.214 & 1.00 & 0.75 \\
HAF4 & 0.167 & 0.75 & 0.60 \\
\hline
\end{tabular}

Table 1. Parameters for HAFs.

The area in the numerical calculation has a length of $2 L(=4 \mathrm{~cm})$ in the axial $(z)$ direction and a width of $2 r_{f}(=125 \mu \mathrm{m})$ in the radial $(r)$ direction. There were 28 and 2,000 divisions in the $r$ and $z$ directions, respectively, and we set the calculation time interval to $1 \mu \mathrm{s}$. We assume that the hot zone is located at the center of the fiber (length $2 L$ ) and that the length $\Delta L$ of the hot zone is $40 \mu \mathrm{m}$. 


\section{Simulation of fiber fuse in HAF}

On the basis of the model described above, we calculated the generation and propagation behavior of a fiber fuse in HAFs with $d_{h}=r_{c}=4.5 \mu \mathrm{m}$ using the FDM.

For reference, we also carried out the calculation for an SMF which has $r_{c}=4.5 \mu \mathrm{m}$, a refractive index difference $\Delta=0.3 \%$, and $A_{e f f}=98.1318 \times 10^{-12} \mathrm{~m}^{2}$.

The calculation using the FDM was conducted in accordance with the procedure in [70]. In the calculation, we set the time interval $\delta t$ to $1 \mu \mathrm{s}$, the step size along the $r$ axis $\delta r$ to $r_{f} / 14$, the step size along the $z$ axis $\delta z$ to $20 \mu \mathrm{m}$, respectively, and assumed that $T_{\mathcal{c}}^{0}=2,923 \mathrm{~K}$ and $T_{a}=298 \mathrm{~K}$.

We estimated the temperature field $T(r, z)$ of HAFs and/or SMF at $t=10 \mathrm{~ms}$ after the incidence of laser light with wavelength $\lambda_{0}=1.55 \mu \mathrm{m}$ and an initial power $P_{0}$ of $4 \mathrm{~W}$. The calculation results for HAF2, HAF3, and HAF4 are shown in Figures 15-17, respectively, and the result for the SMF is shown in Figure 18.

\section{$\mathrm{T}\left(\times 10^{3} \mathrm{~K}\right)$}

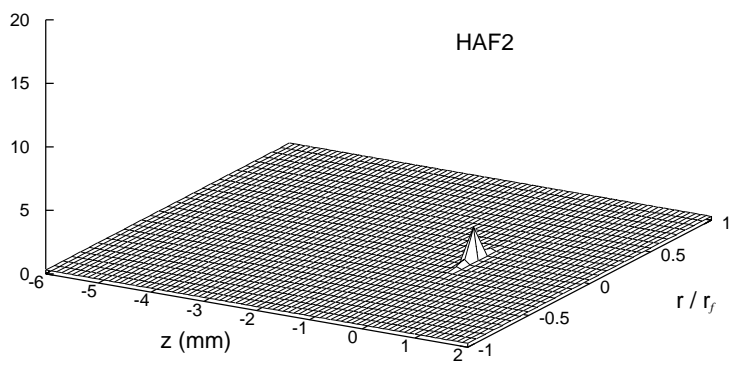

Figure 15. Temperature field in HAF2 after $10 \mathrm{~ms}$ after when $P_{0}=4 \mathrm{~W}$ at $\lambda_{0}=1.55 \mu \mathrm{m}$.

\section{$\mathrm{T}\left(\times 10^{3} \mathrm{~K}\right)$}

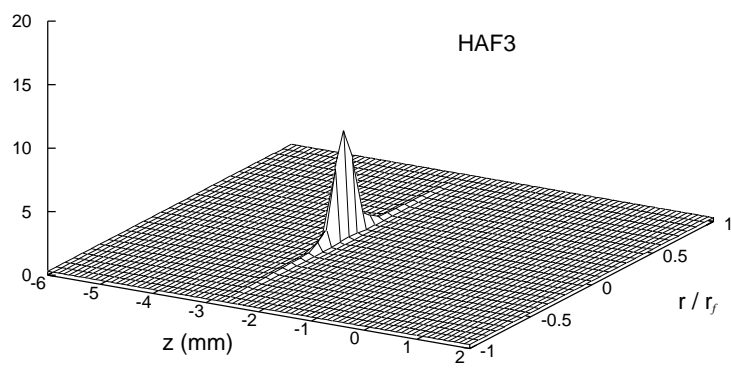

Figure 16. Temperature field in HAF3 after $10 \mathrm{~ms}$ when $P_{0}=4 \mathrm{~W}$ at $\lambda_{0}=1.55 \mu \mathrm{m}$. 


\section{$\mathrm{T}\left(\times 10^{3} \mathrm{~K}\right)$}

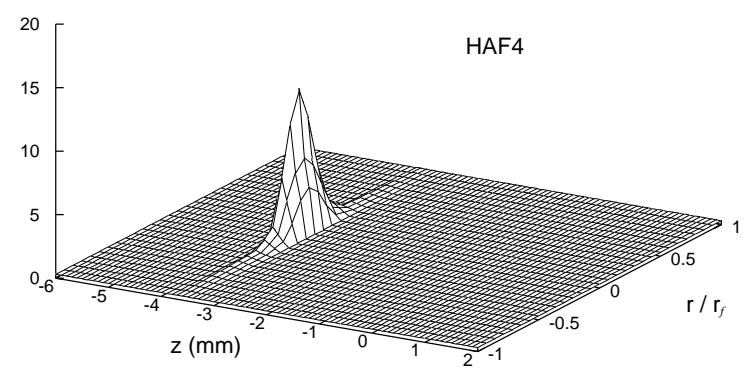

Figure 17. Temperature field in HAF4 after $10 \mathrm{~ms}$ when $P_{0}=4 \mathrm{~W}$ at $\lambda_{0}=1.55 \mu \mathrm{m}$.

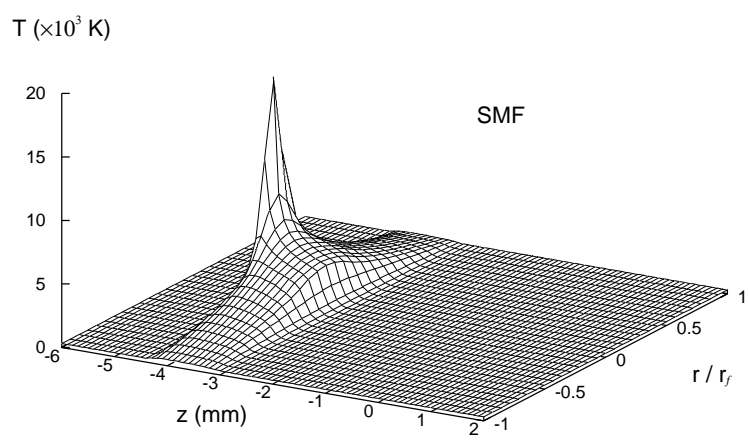

Figure 18. Temperature field in SMF after $10 \mathrm{~ms}$ when $P_{0}=4 \mathrm{~W}$ at $\lambda_{0}=1.55 \mu \mathrm{m}$.

As shown in Figures 15-18, the core center temperature at the thermal peak position of HAF2, HAF3, HAF4, and SMF are 2,923 K, 8,756 K, 11,603 K, and 17,528 K, respectively. The papid rise in the temperature shown in HAF3, HAF4, and SMF initiates the fiber fuse phenomenon. In SMF, the propagation velocity $v_{f}$ of the fiber fuse was estimated to about $0.43 \mathrm{~m} / \mathrm{s}$ from the peak shift distance $(4.3 \mathrm{~mm})$ per $10 \mathrm{~ms}$ of the core center temperature shown in Figure 18. In HAF3 and HAF4, the propagation velocities of the fiber fuse were estimated to about 0.26 and $0.36 \mathrm{~m} / \mathrm{s}$, respectively, by using the same procedure as above.

On the other hand, in HAF2, there is no temperature increase in the core layer, as shown in Figure 15, and it means that a fiber fuse was not generated when $P_{0}=4 \mathrm{~W}$.

We investigated the temperature field $T(r, 0)$ at the end $(z=0 \mathrm{~mm})$ of the hot zone in HAF2 after $10 \mathrm{~ms}$ when $P_{0}=4-10 \mathrm{~W}$ at $\lambda_{0}=1.55 \mu \mathrm{m}$. The calculated temperature fields are shown in Figure 19.

When the power of the light entering HAF2 increases from $4 \mathrm{~W}$ to $5 \mathrm{~W}$, a thermal wave with a peak temperature of higher than $60,000 \mathrm{~K}$ was generated at the end of the hot zone, as 

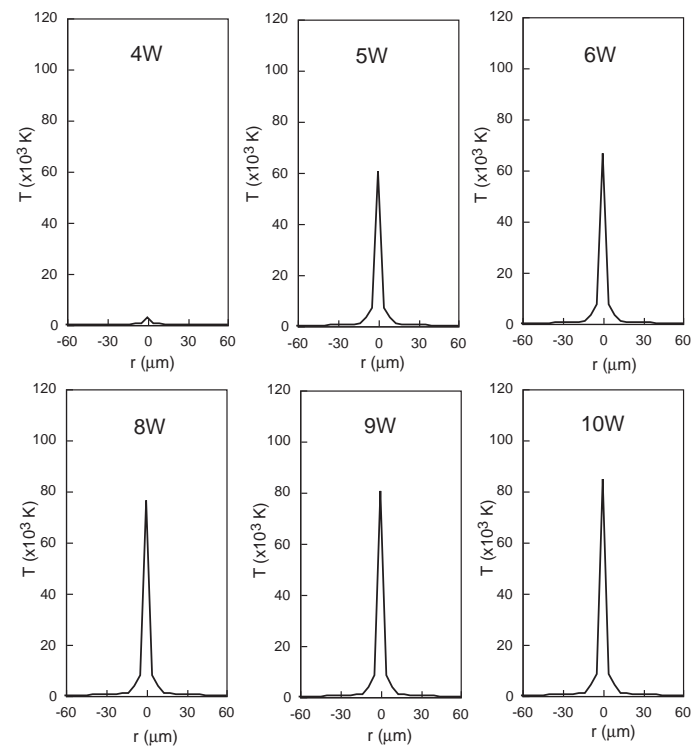

Figure 19. Temperature field at the end of the hot zone in HAF2 after $10 \mathrm{~ms}$ when $P_{0}=4-10 \mathrm{~W}$ at $\lambda_{0}=1.55 \mu \mathrm{m}$.

shown in Figure 19. Figure 20 shows the peak temperature change at the core center $(r=0$ $\mu \mathrm{m}$ ) with passage of time after the incidence of laser light with $P_{0}=5 \mathrm{~W}$ at $\lambda_{0}=1.55 \mu \mathrm{m}$.

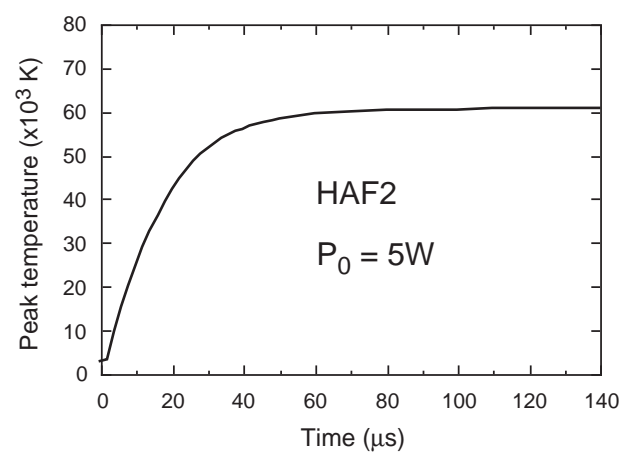

Figure 20. Peak temperature at the core center vs. time after the incidence of laser light with $P_{0}=5 \mathrm{~W}$ at $\lambda_{0}=1.55 \mu \mathrm{m}$.

The core center temperature at the end of the hot zone $(z=0 \mathrm{~mm})$ changes abruptly to a large value of $\geq 50,000 \mathrm{~K}$ after $28 \mu \mathrm{s}$.

Although a thermal wave with a peak temperature of higher than $60,000 \mathrm{~K}$ was generated at the end of the hot zone, it was found that this thermal wave did not increase in size or 
propagate in the negative $z$ direction when $P_{0}$ increased from $5 \mathrm{~W}$ to $10 \mathrm{~W}$, as shown in Figure 19. Such a "stationary" thermal wave was reported by Kashyap [14].

If $P_{0}$ is further increased to $11 \mathrm{~W}$ and above, the thermal wave increases in size and propagates in the negative $z$ direction toward the light source, as shown in Figure 21.

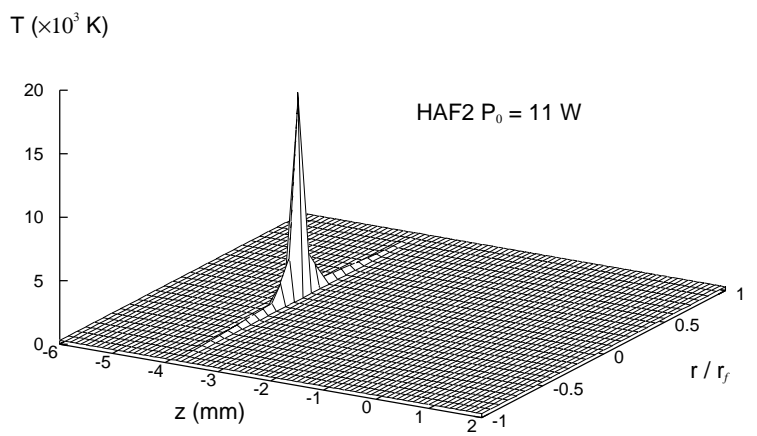

Figure 21. Temperature field in HAF2 after $10 \mathrm{~ms}$ after when $P_{0}=11 \mathrm{~W}$ at $\lambda_{0}=1.55 \mu \mathrm{m}$.

When $P_{0}=11 \mathrm{~W}$, the propagation velocities of the fiber fuse were estimated to about 0.38 $\mathrm{m} / \mathrm{s}$ by using the same procedure as above.

We calculated the power intensity dependence of the propagation velocity $v_{p}$ for each HAF and the SMF at $\lambda_{0}=1.55 \mu \mathrm{m}$. The calculation results for the SMF, HAF2, HAF3, and HAF4 are shown in Figure 22.

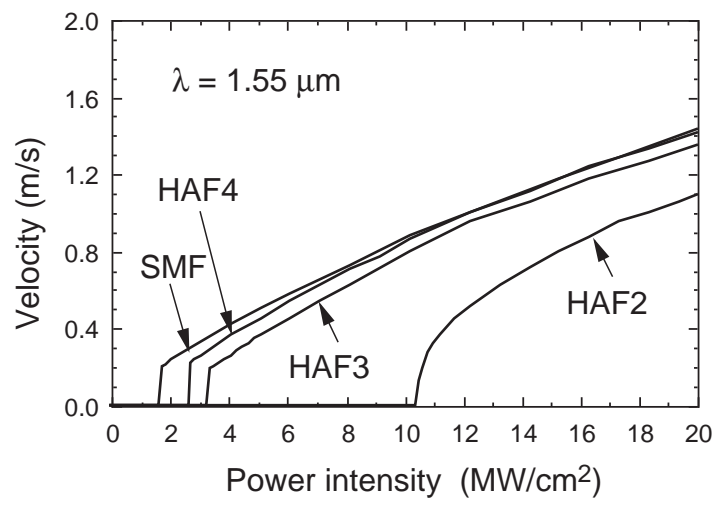

Figure 22. Power intensity vs fiber-fuse propagation velocity for SMF, HAF2, HAF3, and HAF4.

It is clear that the propagation velocity of the HAF4 and/or HAF3 approaches that of the SMF with increasing power intensity.

The threshold power intensity $I_{t h}$ for HAF2, HAF3, HAF4, and SMF are shown in Table 2. 


\begin{tabular}{cc}
\hline Type & $I_{\text {th }}\left(\mathrm{MW} / \mathrm{cm}^{2}\right)$ \\
\hline HAF2 & 10.41 \\
HAF3 & 3.27 \\
HAF4 & 2.65 \\
SMF & 1.63 \\
\hline
\end{tabular}

Table 2. Threshold power intensity for HAFs and SMF.

On the other hand, in HAF2, fiber fuse propagation begins at a threshold power intensity $I_{\text {th }}$ of about $10.4 \mathrm{MW} / \mathrm{cm}^{2}\left(P_{0}=10.2 \mathrm{~W}\right)$, which is much higher than that in HAF3 (about 3.3 $\mathrm{MW} / \mathrm{cm}^{2}$ ) or HAF4 (about $2.7 \mathrm{MW} / \mathrm{cm}^{2}$ ), as shown in Table 2. The $I_{t h}$ of HAF2 is six times that of SMF.

When laser light enters the hot zone of the core layer, heat is produced in the zone by optical absorption of the incident light. In HAF2, the heat generated by optical absorption is effectively dissipated by the heat transfer and radiative transfer between the inner surfaces of the hole layer and the gaseous air. The dissipation of heat in HAF2 is more effective than that in HAF3 or HAF4 because the first cladding layer in HAF2 is thinner than that in HAF3 or HAF4.

Figure 23 shows a schematic view of the relationship between $P_{0}$ and the accumulated heat in the hot zone of the core layer for HAF2 and SMF.

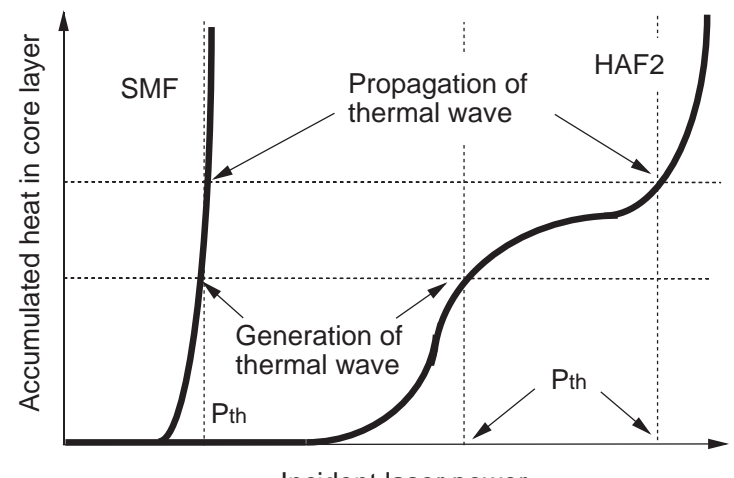

Incident laser power

Figure 23. Schematic view of incident laser power vs accumulated heat in hot zone for HAF2 and SMF.

When the light power is small, the heat generated in the hot zone flows into the adjacent cladding layer, and the rise in the temperature of the zone is prevented. However, if light with a threshold power $P_{t h}$ and above enters the hot zone, it becomes difficult for all the generated heat to escape into the cladding layer, and part of the heat accumulates in the hot zone.

In the SMF, the accumulated heat raises the temperature in the hot zone and a thermal wave, i.e., fiber fuse, is generated at the center of the zone. The thermal wave then rapidly increases in size and starts to propagate toward the light source as shown in Figure 23. 
On the other hand, in HAF2, a large $P_{0}$ value is required to obtain sufficient accumulated heat for both the generation and propagation of a thermal wave, compared with that in the SMF.

Several researchers observed the dynamics of fiber fuse termination near a splice point between a HAF and an SMF by using a high-speed camera [42], [46], [48], [51].

Takenaga et al. reported that when a laser light of $P_{0}=8.1 \mathrm{~W}$ and $\lambda_{0}=1.55 \mu \mathrm{m}$ was input into $\mathrm{HAF} 2+$, a fiber fuse was generated at the splice point between the HAF and the SMF, propagated about $100 \mu \mathrm{m}$ in the direction of the light source, and then stopped [42]. Kurokawa and Hanzawa [46] defined the length between the splice point and the termination point of fiber fuse as a penetration length $L_{p}$. In this case, $L_{p} \simeq 100 \mu \mathrm{m}$.

Similarly, Kurokawa and Hanzawa investigated the power dependence of both the propagation velocity $v_{f}$ for the SMF and $L_{p}$ for HAF2 at $\lambda_{0}=1.48 \mu \mathrm{m}$ [46]. When a laser light of $P_{0}=8.1 \mathrm{~W}$ was input into HAF2, the observed $v_{f}$ for the SMF was $1.1 \mathrm{~m} / \mathrm{s}$ and $L_{p}$ for $\mathrm{HAF} 2$ was $\simeq 80 \mu \mathrm{m}$.

As shown in Figure 19, even if a high power of $9 \mathrm{~W}$ was input into HAF2, a fiber fuse with a high peak temperature of about $80,000 \mathrm{~K}$ was generated at the center of the heated core, but it did not propagate forward the light source. This phenomenon, in which the propagation of a fiber fuse is controlled, is in good agreement with the experimental results observed by Takenaga et al. and Kurokawa and Hanzawa [46] for HAF2.

On the other hand, Kurokawa and Hanzawa reported that $v_{f}=1.3 \mathrm{~m} / \mathrm{s}$ and $L_{p}=110 \mu \mathrm{m}$ when a laser light of $P_{0}=12.0 \mathrm{~W}(6.0 \mathrm{~W}$ at both $1.48 \mu \mathrm{m}$ and $1.55 \mu \mathrm{m})$ was input into HAF2 [46]. This behavior for HAF2 cannot be explained by our calculation described above. As shown in Figure 22, a fiber fuse, generated at the splice point between the HAF2 and the SMF, was expected to maintain propagation in the direction of the light source when $I_{t h}=$ 12.2 $\mathrm{MW} / \mathrm{cm}^{2}\left(P_{0}=12.0 \mathrm{~W}\right)$. However, it was reported that the fiber fuse propagated only about $120 \mu \mathrm{m}$, and then stopped.

Furthermore, they reported that the hole part in the HAF disappeared in the domain in which the fiber fuse penetrated [46]. They considered that the plasma density of the core decreased in connection with the disappearance of the hole part and that the propagation of a fiber fuse can be controlled even if a high power of $10 \mathrm{~W}$ order is input into an HAF. In practice, they observed the dynamics of fiber fuse termination near the splice point between HAF2 and the SMF and found that the termination was accompanied by the evolution of a gas jet in the case of $P_{0}=12 \mathrm{~W}[48]$ and $18.1 \mathrm{~W}(6.6 \mathrm{~W}$ at $1.48 \mu \mathrm{m}$ and $11.5 \mathrm{~W}$ at $1.55 \mu \mathrm{m})$ [51].

In order for the hole part to disappear with the gas jet, it is necessary for the (first) cladding layer inscribed in this hole part to be destroyed by the incident high power.

We considered the destruction of the cladding layer using our heat conduction model, the results of which are described below.

\section{Destruction mechanism of inner cladding layer of HAF}

The internal core space of an HAF heated to an elevated temperature is shielded from the external conditions. Thus, with increasing temperature, the internal pressure increases and 
the internal volume decreases. Dianov et al. reported an internal core temperature of about $10,000 \mathrm{~K}$ and an internal pressure of about 10,000 atmospheres (1 GPa) at the time of fiber fuse evolution [72].

In HAF2, $D_{\text {hole }} / 2=9.0 \mu \mathrm{m}$ and $r_{c}=4.5 \mu \mathrm{m}$. Therefore, the thickness $h$ of the first cladding layer was $4.5 \mu \mathrm{m}$ before the core was heated to a high temperature. When the core is heated to a high temperature and the internal pressure $p$ reaches $1 \mathrm{GPa}$, the first cladding layer is partially melted by heat transmitted from the core and $h$ becomes smaller than its initial value $(4.5 \mu \mathrm{m})$.

We consider a tensile stress $\sigma_{\theta}$ acting on the inner wall of the first cladding layer with thickness $h$, as shown in Figure 24 .

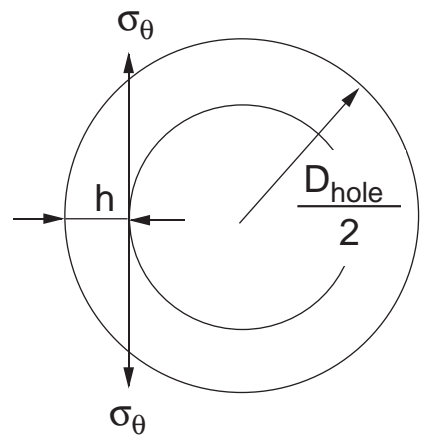

Figure 24. Tensile stress acting on inner wall of first cladding layer in HAF.

$\sigma_{\theta}$ is related to $p$ by the following expression [96]:

$$
\sigma_{\theta}=\frac{D_{\text {hole }}^{2}-2 D_{\text {hole }} h+2 h^{2}}{2 D_{\text {hole }} h-2 h^{2}} \cdot p .
$$

$\sigma_{\theta}$ increases with increasing $p$. If $\sigma_{\theta}$ exceeds the ideal fracture strength $\sigma_{0}$ of the silica glass, a crack will generate on the inner wall of the first cladding layer.

On the other hand, it is well known for various solid materials that the $\sigma_{0}$ value is related to the Young's modulus $E$ of the material by the following equation [97]:

$$
\sigma_{0} \approx E / 10
$$

By using Eq. (31) and $E=73 \mathrm{GPa}$ for silica glass, we can estimate $\sigma_{0}$ to be approximately 7.3 GPa.

For the HAF2, we estimated the relationship between $h$ and the tensile stress $\sigma_{\theta}$ acting on the inner wall of the first cladding layer for $p=1 \mathrm{GPa}$ using Eq. (30). The calculation result is shown in Figure 25. 


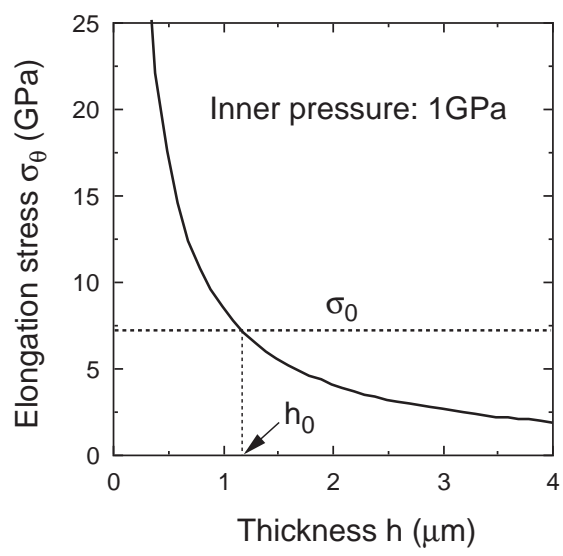

Figure 25. Thickness vs tensile stress acting on inner wall of cladding layer in HAF2.

$\sigma_{\theta}$ increases with decreasing $h$. It was found that when $h$ decreases to a critical thickness $h_{0}$ $(\sim 1.2 \mu \mathrm{m}), \sigma_{\theta}$ becomes to $\sigma_{0}(\sim 7.3 \mathrm{GPa})$. That is, $\sigma_{\theta}$ becomes larger than $\sigma_{0}$ when $h<h_{0}$. This means that the inner wall of the first cladding layer will crack and be destroyed when $h<h_{0}$.

Silica glass has a melting temperature of $T_{m}=1,973 \mathrm{~K}$. If solid silica glass is heated above $T_{m}$, it will become a liquid "melt" and its mechanical properties, such as tensile tolerance, will be lost.

If the heat conduction model discussed above is used, the temperature distribution along the internal radial direction can be estimated for the HAF2.

We can estimate the radial distance (equivalent to $h$ in Figure 24) from the outer wall of the first cladding layer with temperature $T_{a}$ to an inner point at which $T$ reaches $T_{m}$ using the heat conduction model. Then, the minimum power of incident laser light necessary for $h<h_{0}$ to be satisfied can be determined by estimating the $h$ value when laser light with various powers enters the HAF2.

For incident laser powers $P_{0}$ of $4-10 \mathrm{~W}$ with $\lambda_{0}=1.55 \mu \mathrm{m}$, the temperature distribution in the first cladding layer as a function of the radial distance $h^{\prime}$ was calculated for the HAF2. The result is shown in Figure 26.

The horizontal axis $h^{\prime}$ in Figure 26 represents the distance between the outer wall of the first cladding layer and an inner point located closer to the core center.

When $P_{0}$ is $4 \mathrm{~W}$ or less, the temperature $T$ in the cladding layer is lower than $T_{m}$, and the cladding layer is not destroyed.

On the other hand, when $P_{0}$ is $5 \mathrm{~W}$ and above, $T$ increases with increasing $h^{\prime}$. When $P_{0}=10$ $\mathrm{W}, T$ reaches $\sim T_{m}$ at $h^{\prime} \sim 1.2 \mu \mathrm{m}$. This value of $h^{\prime}(\sim 1.2 \mu \mathrm{m})$ is the same as the threshold value of $h_{0}(\sim 1.2 \mu \mathrm{m})$ for crack generation on the inner wall of the cladding layer. Therefore, the destruction of the cladding layer is predicted when laser light with $P_{0} \geq 10 \mathrm{~W}$ enters the HAF2. 


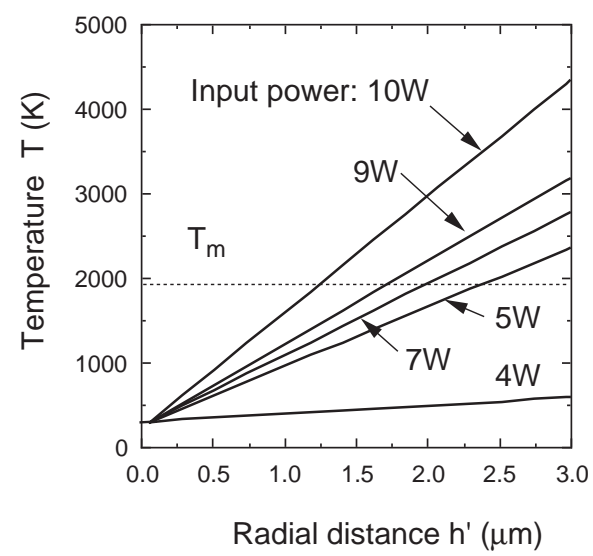

Figure 26. Temperature field in first cladding layer of HAF2 when $P_{0}=4-10 \mathrm{~W}$ at $\lambda_{0}=1.55 \mu \mathrm{m}$.

If a thermal wave propagates along the fiber axis, because of the pressure difference of about 10,000 atmospheres between the internal core and the air hole layer, the destruction of the cladding layer will change the propagation direction of the thermal wave from the axial direction to the radial direction. As a result, the thermal wave will propagate toward the air hole layer with a low pressure (about 1 atmosphere). This is the reason for the observation of a gas jet reported by Kurokawa et al. [48].

When the thermal wave propagates into the air hole layer, the hole layer disappears as a result of thermal heating and the core temperature decreases owing to the departure of the thermal wave. Such cooling of the core will prevent the generation of a new thermal wave in the core, and the propagation of the thermal wave will stop at this time.

Kurokawa and Hanzawa [46] reported that when laser light with a high power entered HAF2, the increase in penetration length started at an incident power of $8 \mathrm{~W}$.

As described above, if the incident power increases from $9 \mathrm{~W}$ to $10 \mathrm{~W}$, the cladding layer is destroyed and the direction of propagation of the thermal wave changes to the radial direction, and the air hole layer vanishes owing to the melting of the cladding layer.

There is a slight time delay $\tau$ for an crack propagating from the inner surface to the outer surface of the first cladding layer. The crack generated on the inner surface of the first cladding layer grows and propagates to the outer surface of the cladding layer. When the crack reaches the outer surface, the first cladding layer is destroyed because of the pressure difference of about 10,000 atmospheres between the internal core and the air hole layer.

The crack propagation rate $V_{c}$ of the silica glass is related to the sonic rate $V_{s}$ of the glass as follows [98]:

$$
0 \leq V_{c} \leq 0.38 V_{s}
$$

The value of $V_{s}$ for silica glass is $5,570 \mathrm{~m} / \mathrm{s}$. For a crack propagating through a small length of $\sim 1.2 \mu \mathrm{m}\left(=h_{0}\right)$, the minimum time delay $\tau_{m}$ was estimated to be 


$$
\tau_{m} \equiv \frac{h_{0}}{0.38 V_{s}}=5.7 \times 10^{-10} \mathrm{~s}
$$

This time delay is not dependent on the incident power, as indicated by Eq. (32), and the propagation velocity $v_{f}$ of the thermal wave increases with increasing incident power.

We assumed that $\tau$ for the HAF2 corresponded to the time (50-90 $\mu \mathrm{s})$ for rapid rise in the core temperature after the incidence of fiber fuse, which propagated in the SMF. If we assume that $\tau \sim 80 \mu \mathrm{s}$ and the penetration length $L_{p}$ is the product of $v_{f}$ and $\tau$, the $L_{p}$ values at a incident light of $P_{0}=8.1 \mathrm{~W}$ and $12.0 \mathrm{~W}$ are $88 \mu \mathrm{m}$ and $104 \mu \mathrm{m}$. These values are fairly good agreement with the experimental results $(\sim 80 \mu \mathrm{m}$ and $110 \mu \mathrm{m})$ reported by Kurokawa and Hanzawa [46].

In closing, we should comment on the fiber fuse propagation with a long-period damage track, which was observed in the HAF2 with $d_{h}$ of smaller than $r_{c}$ [46], [48]-[50]. The most striking characteristic of this phenomenon is the long period (several $100 \mu \mathrm{m}$ order) of the cavities, which were generated by entering of a relatively low power (about 1.5-4.5 W) into HAF2.

The long period damage tracks such as those in HAF2 were reported by Bufetov et al. [99]. They found that such a phenomenon was observed as a result of the interference of $\mathrm{LP}_{01}$ and $\mathrm{LP}_{02}$ modes excited in an optical fiber with a $\mathrm{W}$-index profile. However HAF2 is a step-index optical fiber, and only $\mathrm{LP}_{01}$ (or $\mathrm{TE}_{11}$ ) mode can be excited in HAF2 at 1.48 and/or $1.55 \mu \mathrm{m}$. Therefore, it is very difficult to consider that the mode interference is responsible for the long period damage tracks observed in HAF2.

Instead of the mode interference, we consider that this phenomenon may relate to a thermal lense effect [63], [101]. The focal length $F$ of thermal lense effect is given by (see Appendix)

$$
F=\frac{n_{0} \pi \kappa \omega_{0}^{2}}{\alpha P l(\partial n / \partial T)}
$$

where $n_{0}(=1.46)$ is the characteristic refractive index of the core layer, $P$ is the incident power of the light reflecting from the cavity wall, which is estimated by Eq. (24). $\omega_{0}(\sim 4.5 \mu \mathrm{m})$ is the spot size radius of the laser beam when optical power in the optical fiber was assumed to take on Gaussian distribution, $\partial n / \partial T\left(=1.23 \times 10^{-5} \mathrm{~K}^{-1}[5]\right)$ is the thermal coefficient of refractive index for silica glass, and $l$ is the length of the heating core, where $\alpha$ exhibits large value.

As $F$ is inversely as the product of $\alpha$ and $P$, large $F$ value may be obtained by small $\alpha$ and/or $P$ value, which is comparable with observed long period of the cavities. If we assume $\lambda=9.2$ $\mathrm{W} / \mathrm{mK}$ [5], $l=20 \mu \mathrm{m}$, and $\alpha=5 \times 10^{4} \mathrm{~m}^{-1}$, the $F$ value at $P=0.158 \mathrm{~W}\left(P_{0}=4.5 \mathrm{~W}\right)$ can be estimated to about $440 \mu \mathrm{m}$ by using Eq. (34). This value is fairly good agreement with the observed period $(460 \mu \mathrm{m})$ of the cavities [46], [48]-[50].

The cause of mechanism of the long-period damage track has yet to be sufficiently clarified. It largely depends upon future multilateral studies. 


\section{Conclusions}

We investigated the unsteady thermal conduction status in a single-mode optical fiber by numerical computation in order to visualize the mode of fiber fuse propagation. We assumed that the vitreous silica optical fiber underwent pyrolysis at elevated temperatures to form $\mathrm{SiO}_{x}(x \sim 1)$. We also proposed a model in which the optical absorption coefficient of the core layer increased with increasing molar concentration of $\mathrm{SiO}_{x}$. By using the model, we calculated the temperature distribution in the fiber with the explicit finite-difference method. It was found that when a short core with $40 \mu \mathrm{m}$ length was heated to $2,923 \mathrm{~K}$ and a 2 $\mathrm{W}$ laser light (wavelength of $1.064 \mu \mathrm{m}$ ) entered the core layer of an SMF-28 optical fiber, a thermal wave, i.e., a fiber fuse, with a peak temperature of about $34,000 \mathrm{~K}$ was generated at the boundary of the heating region near the light source. The fiber fuse was enlarged and propagated toward the light source at a rate of about $0.54 \mathrm{~m} / \mathrm{s}$. The calculated propagation velocity of the fiber fuse was in agreement with the experimental value. Moreover, the average temperature of the radiated region of the core layer was less than $7,000 \mathrm{~K}$ at a time of $4 \mathrm{~ms}$ after the generation of the fiber fuse and gradually approached a temperature of about $5,700 \mathrm{~K}$. The final average temperature was close to the experimentally reported values.

We evaluated the threshold power of fiber fuse propagation in hole-assisted fibers (HAFs) using the finite-difference method and the model proposed by Takara et al. The HAFs with ratios of hole-space distance to core diameter of 3 and 4 exhibited fiber fuse propagation when a $1.55 \mu \mathrm{m}$ laser with a power of $4 \mathrm{~W}$ was input into the core layer, as observed for an SM optical fiber.

On the other hand, the HAF with a ratio of hole-space distance to core diameter of 2 exhibited no fiber fuse generation or propagation when a $1.55 \mu \mathrm{m}$ laser with a power of $10 \mathrm{~W}$ was input into the core layer.

Furthermore, when the incident power was $5 \mathrm{~W}$ and above, the temperature of the central core increased owing to the absorption of a large amount of power, causing the melting of the first cladding layer adjacent to the heated core. Thus, the thickness of the first cladding layer decreased below the value at which the solid cladding layer could be maintained, and the cladding layer was destroyed following the disappearance of the air hole layer. The destruction of the cladding layer caused the direction of the thermal wave to change from the axial direction to the radial direction, stopping the propagation of the thermal wave. By using this phenomenon, Kurokawa and Hanzawa proposed a novel fiber fuse terminotor composed of a short length of HAF [100].

\section{Appendix: Focal length of thermal lens effect}

If part of the core layer is heated by light absorption, the refractive-index gradient in the core is induced by the thermal coefficient of the refractive index $\partial n / \partial T$ of the silica glass and the temperature distribution $\Delta T$ in the core layer. The refractive index $n$ of the heated core is expressed as follows:

$$
n(r, t)=n_{0}+\frac{\partial n}{\partial T} \Delta T(r, t)
$$

where $n_{0}(=1.46)$ is the characteristic $n$ value of the core layer, $r$ is the radial distance from the center of the optical fiber, and $t$ is time, respectively. 
If we assume that optical power in the optical fiber takes on Gaussian distribution, $\Delta T$ in the core layer is given by [63], [101]

$$
\Delta T(r, t)=\frac{\alpha P}{4 \pi \lambda}\left[\ln \left(1+\frac{8 D t}{\omega_{0}^{2}}\right)-\frac{16 D t}{\omega_{0}^{2}+8 D t} \frac{r^{2}}{\omega_{0}^{2}}\right]
$$

where $\alpha$ is the absorption coefficient, $P$ is the incident optical power, $\omega_{0}$ is the spot size radius of the laser beam, and $\lambda$ is the thermal conductivity of the silica glass, respectively. Parameter $D=\lambda / C_{p} \rho$, where $C_{p}$ and $\rho$ are the specific heat and dnsity of the silica glass.

Substitution of Eq. (36) into Eq. (35) gives

$$
\begin{aligned}
& n \cong n_{0}\left[1+\delta\left(\frac{r}{\omega_{0}}\right)^{2}\right] \\
& \delta=-\frac{2 \alpha P}{4 n_{0} \pi \lambda}\left(\frac{\partial n}{\partial T}\right) \frac{8 D t}{\omega_{0}^{2}+8 D t}
\end{aligned}
$$

When refractive index of the core layer takes a radial distribution as shown in Eq. (37), propagating laser beam will be focussed as a result of the thermal lens effect. In this case, the focal length $F$ is given by [63], [101]

$$
\begin{aligned}
F(t) & =\frac{n_{0} \pi \lambda \omega_{0}^{2}\left(\omega_{0}^{2}+8 D t\right)}{\alpha P l(\partial n / \partial T)(8 D t)}=F_{\infty}\left[1+\frac{t_{c}}{2 t}\right] \\
F_{\infty} & =\frac{n_{0} \pi \lambda \omega_{0}^{2}}{\alpha P l(\partial n / \partial T)^{2}} \\
t_{c} & =\frac{\omega_{0}^{2}}{4 D}
\end{aligned}
$$

where $l$ is the length of the heating core, where $\alpha$ exhibits large value. In typical SM fiber, $\lambda=9.2 \mathrm{~W} / \mathrm{mK}, C_{p}=788 \mathrm{~J} / \mathrm{kgK}, \rho=2,200 \mathrm{~kg} / \mathrm{m}^{3}$ [5], and $\omega_{0} \sim 4.5 \mu \mathrm{m}$. If we insert these values into Eqs. (39)-(41), we obtain $t_{c} \sim 0.95 \mu \mathrm{s}$. This means that $F \cong F_{\infty}$ when $t$ is $10 \mu \mathrm{s}$ or above. If we assume $P=2 \mathrm{~W}, l \sim 40 \mu \mathrm{m}, \alpha=5.6 \times 10^{4} \mathrm{~m}^{-1}$ [5], and $\partial n / \partial T=1.23 \times 10^{-5}$ $\mathrm{K}^{-1}[5], F$ is given by

$$
F \cong F_{\infty} \sim 15.5 \mu \mathrm{m}
$$

This $F$ value is of the same order of the observed interval and/or large front size of the cavities [11], [23].

\section{Author details}

Yoshito Shuto

Ofra Project, Iruma, Japan 


\section{References}

[1] A. Asano, T. Kobayashi, E. Yoshida, and Y. Miyamoto. Ultra-high capacity optical transmission technologies for $100 \mathrm{Tbit} / \mathrm{s}$ optical transport networks, IEICE Trans. Commun. 2011; E94-B(2): 400-408.

[2] T. Morioka. New generation optical infrastructure technologies: "EXAT initiative" toward 2020 and beyond, OptoElectron. Commun. Conf. 2009 (OECC 2009): FT4.

[3] R. Kashyap and K. J. Blow. Observation of catastrophic self-propelled self-focusing in optical fibres, Electron. Lett. 1988; 24(1): 47-49.

[4] R. Kashyap. Self-propelled self-focusing damage in optical fibres, Proc. Xth Int. Conf. Lasers 1988: 859-866.

[5] D. P. Hand and P. St. J. Russell. Solitary thermal shock waves and optical damage in optical fibers: the fiber fuse, Opt. Lett. 1988; 13(9): 767-769.

[6] D. P. Hand and P. St. J. Russell. Soliton-like thermal shock-waves in optical fibers: Origin of periodic damage tracks, Eur. Conf. Opt. Commun. 1988: 111-114.

[7] D. D. Davis, S. C. Mettler, and D. J. DiGiovanni. Experimental data on the fiber fuse, in H. E. Bennett, A. H. Guenther, M. R. Kozlowski, B. E.. Newnam, and M. J.Soileau (eds), Proc. Soc. Photo-Opt. Instrum. Eng. 1995; Vol. 2714: 202-210.

[8] D. D. Davis, S. C. Mettler, and D. J. DiGiovanni. A comparative evaluation of fiber fuse models, in H. E. Bennett, A. H. Guenther, M. R. Kozlowski, B. E.. Newnam, and M. J.Soileau (eds), Proc. Soc. Photo-Opt. Instrum. Eng. 1996; Vol. 2966: 592-606.

[9] S. Todoroki. Animation of fiber fuse damage, demonstrating periodic void formation, Opt. Lett. 2005; 30(19): 2551-2553.

[10] S. Todoroki. In-situ observation of fiber fuse propagation, Jpn. J. Appl. Phys. 2005; 4(6A): 4022-4024.

[11] S. Todoroki. Origin of periodic void formation during fiber fuse, Opt. Express 2005; 13(17): 6381-6389.

[12] S. Todoroki. Transient propagation mode of fiber fuse leaving no voids, Opt. Express 2005; 13(23): 9248-9256.

[13] S. Todoroki. In situ observation of modulated light emmission of fiber fuse synchronized with void train over hetero-core splice point, PLos ONE 2008; 3(9): e3276-1-4.

[14] R. Kashyap. The fiber fuse - from a curious effect to a critical issue: a 25th year retrospective, Opt. Express 2013; 21(5): 6422-6441.

[15] S. Todoroki. Fiber fuse propagation behavior, in Y. Moh, S. W. Harun, and H. Arof (eds), Selected Topics on Optical Fiber Technology, InTech, Croatia 2012: 551-570. 
[16] P. André, A. Rocha, F. Domingues, and M. Facão. Thermal effects in optical fibres, in M. A. D. Bernardes (eds), Developments in Heat Transfer, InTech, Croatia 2011: 1-20.

[17] S. Todoroki. Fiber Fuse: Light-Induced Continuous Breakdown of Silica Glass Optical Fiber. NIMS Monographs. Springer: Tokyo; 2014.

[18] T. J. Driscoll, J. M. Calo, and N. M. Lawandy. Explaining the optical fuse, Opt. Lett. 1991; 16(13): 1046-1048.

[19] R. Kashyap, A. Sayles, and G. F. Cornwell. Heat flow modeling and visualization of catastrophic self-propagating damage in single-mode optical fibres at low powers, in H. E. Bennett, A. H. Guenther, M. R. Kozlowski, B. E.. Newnam, and M. J.Soileau (eds), Proc. Soc. Photo-Opt. Instrum. Eng. 1996; Vol. 2966: 586-591.

[20] E. M. Dianov, I. A. Bufetov, A. A. Frolov, V. G. Plotnichenko, V. M. Mashinskii, M. F. Churbanov, and G. E. Snopatin. Catastrophic destruction of optical fibres of various composition caused by laser radiation, Quantum Electron. 2002; 32(6): 476-478.

[21] E. M. Dianov, I. A. Bufetov, A. A. Frolov, V. M. Mashinskii, V. G. Plotnichenko, M. F. Churbanov, and G. E. Snopatin. Catastrophic destruction of fluoride and chalcogenide optical fibres, Electron. Lett. 2002; 38(15): 783-784.

[22] R. Kashyap. High average power effects in optical fibres and devices, in H. G. Limberger, and M. J. Matthewson (eds), Proc. Soc. Photo-Opt. Instrum. Eng. 2003; Vol. 4940: 108-117.

[23] R. M. Atkins, P. G. Simpkins, and A. D. Yabon. Track of a fiber fuse: a Rayleigh instability in optical waveguides, Opt. Lett. 2003; 28(12): 974-976.

[24] K. Seo, N. Nishimura, M. Shiino, R. Yuguchi, and H. Sasaki. Evaluation of high-power endurance in optical fiber links, Furukawa Rev. 2003; (24): 17-22.

[25] M. M. Lee, J. M. Roth, T. G. Ulmer, and C. V. Cryan. The fiber fuse phenomenon in polarization-maintaining fibers at $1.55 \mu \mathrm{m}$, Proc. Conf. on Lasers and Electro-Optics 2006 (CLEO): JWB66.

[26] E. D. Bumarin and S. I. Yakovlenko. Temperature distribution in the bright spot of the optical discharge in an optical fiber, Laser Phys. 2006; 16(8): 1235-1241.

[27] I. A. Bufetov, A. A. Frolov, E. M. Dianov, V. E. Frotov, and V. P. Efremov. Dynamics of fiber fuse propagation, Optical Fiber Commun./Nat. Fiber Optic Engineers Conf. 2005 (OFC/NFOEC 2005): OThQ7.

[28] E. M. Dianov, V. E. Frotov, I. A. Bufetov, V. P. Efremov, A. E. Rakitin, M. A. Melkumov, M. I. Kulish, and A. A. Frolov. High-speed photography, spectra, and temperature of optical discharge in silica-based fibers, IEEE Photon. Technol. Lett. 2006; 18(6): 752-754.

[29] J. Wang, S. Gray, D. Walton, and L. Zentero. Fiber fuse in high power optical fiber, in M.-J. Li, P. Shum, I. H. White, and X. Wu (eds), Proc. Soc. Photo-Opt. Instrum. Eng. 2008; Vol. 7134: 71342E-1-9. 
[30] K. S. Abedin and M. Nakazawa. Real time monitoring of a fiber fuse using an optical time-domain reflectometer, Opt. Express 2010; 18(20): 21315-21321.

[31] P. S. André, M. Facão, A. M. Rocha, P. Antunes, and A. Martins. Evaluation of the fuse effect propagation in networks infrastructures with different types of fibers, Optical Fiber Commun./Nat. Fiber Optic Engineers Conf. 2010 (OFC/NFOEC 2010): JWA10.

[32] P. S. André, A. M. Rocha, F. Domingues, and A. Martins. Improved thermal model for optical fibre coating owing to small bending diameter and high power signals, Electron. Lett. 2010; 46(10): 695-696.

[33] M. Yamada, O. Koyama, Y. Katsuyama, and T. Shibuya. Heating and burning of optical fiber by light scattered from bubble train formed by optical fiber fuse, Optical Fiber Commun./Nat. Fiber Optic Engineers Conf. 2011 (OFC/NFOEC 2011): JThA1.

[34] A. M. Rocha, P. Antunes, F. Domingues, M. Facão, and P. S. André. Detection of fiber fuse using FBG sensors, IEEE Sensors J. 2011; 11(6): 1390-1394.

[35] A. M. Rocha, F. Domingues, M. Facão, and P. S. André. Threshold power of fiber fuse effect for diffent types of optical fiber, Int. Conf. on Transparent Optical Networks 2011 (ICTON 2011): Tu.P.13.

[36] W. Ha, Y. Jeong, and K. Oh. Fiber fuse in hollow optical fibers, Opt. Lett. 2011; 36(9): 1536-1538.

[37] S. Todoroki. Threshold power reduction of fiber fuse propagation through a white tight-buffered single-mode optical fiber, IEICE Electron. Express 2011; 8(23): 1978-1982.

[38] F. Domingues, A. R. Frias, P. Antunes, A. O. P. Sousa, R. A. S. Ferreira, and P. S. André. Observaion of fuse effect discharge zone nonlinear velocity regime in erbium-doped fibres, Electron. Lett. 2012; 48(20): 1295-1296.

[39] S. Todoroki. Fiber fuse propagation modes in typical single-mode fibers, Optical Fiber Commun./Nat. Fiber Optic Engineers Conf. 2013 (OFC/NFOEC 2013): JW2A.

[40] E. M. Dianov, I. A. Bufetov, A. A. Frolov, Y. K.Chamorovsky, G. A. Ivanov, and I. L. Vorobjev. Fiber fuse effect in microstructured fibers, IEEE Photon. Technol. Lett. 2004; 16(1): 180-181.

[41] K. Nakajima, K. Hogari, J. Zhou, K. Tajima, and I. Sankawa. Hole-assisted fiber design for small bending and splice losses, IEEE Photon. Technol. Lett. 2003; 15(12): 1737-1739.

[42] K. Takenaga, S. Tanigawa, S. Matsuo, M. Fujimaki, and H. Tsuchiya. Fiber fuse phenomenon in hole-assisted fibers, in Technical Digest of European Conf. Opt. Commun. 2008 (ECOC 2008): P.1.14.

[43] N. Hanzawa, K. Kurokawa, K. Tsujikawa, T. Matsui, and S. Tomita. Suppression of fiber fuse propagation in photonic crystal fiber (PCF) and hole assisted fiber (HAF), Proc. 15th Microoptics Conf. 2009 (MOC'09): M7. 
[44] H. Takara, H. Masuda, H. Kanbara, Y. Abe, Y. Miyamoto, R. Nagase, T. Morioka, S. Matsuoka, M. Shimizu, and K. Hagimoto. Evaluation of fiber fuse characteristics of hole-assisted fiber for high power optical transmission systems, in Technical Digest of European Conf. Opt. Commun. 2009 (ECOC 2009): 918-919.

[45] N. Hanzawa, K. Kurokawa, K. Tsujikawa, T. Matsui, K. Nakajima, S. Tomita, and M. Tsubokawa. Suppression of fiber fuse propagation in hole assisted fiber and photonic crystal fiber, IEEE J. Lightwave Technol. 2010; 28(15): 2115-2120.

[46] K. Kurokawa and N. Hanzawa. Fiber fuse propagation and its suppression in hole assisted fibers, IEICE Trans. Commun. 2011; E94-B(2): 384-391.

[47] K. Takenaga, S. Tanigawa, S. Matsuo, and M. Fujimaki. Fiber fuse phenomenon in hole-assisted fibers, Fujikura Technical Rev. 2011: 12-15.

[48] K. Kurokawa, N. Hanzawa, K. Tsujikawa, and S. Tomita. Hole-size dependence of fiber fuse propagation in hole-assisted fiber (HAF), Proc. 17th Microoptics Conf. 2011 (MOC'11): H-30.

[49] N. Hanzawa, K. Kurokawa, K. Tsujikawa, K. Takenaga, S. Tanigawa, S. Matsuo, and S. Tomita. Observation of a propagation mode of a fiber fuse with a long-period damage track in hole-assisted fiber, Opt. Lett. 2010; 35(12): 2004-2006.

[50] K. Kurokawa, N. Hanzawa, K. Tsujikawa, and S. Tomita. Power dependence of fiber fuse propagation with a long-period damage track in hole-assisted fiber, IEICE Electron. Express 2011; 8(11): 802-807.

[51] K. Kurokawa. Optical fiber for high-power optical communication, Crystals 2012; 2: 1382-1392.

[52] S. I. Yakovkenko. On reasons for strong absorption of light in an optical fibre at high temperature, Quantum Electron. 2004; 34(9): 787-789.

[53] S. I. Yakovkenko. Plasma behind the front of a damage wave and the mechanism of laser-induced production of a chain of caverns in an optical fibre, Quantum Electron. 2004; 34(8): 765-770.

[54] S. I. Yakovkenko. Mechanism for the void formation in the bright spot of a fiber fuse, Laser Phys. 2006; 16(3): 474-476.

[55] S. I. Yakovkenko. Physical processes upon the optical discharge propagating in optical fiber, Laser Phys. 2006; 16(9): 1273-1290.

[56] M. Facão, A. Rocha, and P. André. Traveling solution of the fuse effect in optical fibers, IEEE/OSA J. Lightwave Technol. 2011; 29(1): 109-114.

[57] A. Ankiewicz, W. Chen, P. St. J. Russell, M. Taki, and N. Akhmediev. Velocity of heat dissipative solitons in optical fibers, Opt. Lett. 2008; 33(19): 2176-2178. 
[58] E. M. Dianov, V. E. Frotov, I. A. Bufetov, V. P. Efremov, A. A. Frolov, M. Y. Schelev, and V. I. Lozovoi. Detonation-like mode of the destruction of optical fibers under intense laser radiation, JETP Lett. 2006; 83(2): 75-78.

[59] B. J. Matkowsky and G. I. Sivashinsky. Propagation of a pulsating reaction front in solid fuel combustion, SIAM J. Appl. Math. 1978; 35(3): 465-478.

[60] S. Ei and M. Mimura. Relaxation oscillations in combustion models of thermal self-ignition, J. Dynamics and Differential Equations 1992; 4(1): 191-229.

[61] R. O. Weber, G. N. Mercer, H. S. Sidhu, and B. F. Gray. Combustion waves for gases (Le $=1$ ) and solids $($ Le $\rightarrow \infty)$, Proc. R. Soc. Lond. A 1997; 453: 1105-1118.

[62] N. Akhmediev, P. St. J. Russell, M. Taki, and J. M. Soto-Crespo. Heat dissipative solitons in optical fibers, Phys. Lett. A 2008; 372: 1531-1534.

[63] M. Katayama. Laser Chemistry; Nonlinear Spectroscopy and Laser Induced Chemical Processes. Chap. 11. Syokabo, Inc.; Tokyo: 1985.

[64] A. E. Owen and R. W. Douglas. The electrical properties of vitreous silica, J. Soc. Glass Technol. 1959; 43: 159-178.

[65] R. H. Doremus. Ionic transport in amorphous oxides, J. Electrochem. Soc. 1968; 115: 181-186.

[66] Y. Shuto, S. Yanagi, S. Asakawa, M. Kobayashi, and R. Nagase. Simulation of fiber fuse phenomenon in single-mode optical fibers, IEEE/OSA J. Lightwave Technol. 2003; 21(11): 2511-2517.

[67] Y. Shuto, S. Yanagi, S. Asakawa, and R. Nagase. Generation mechanism on fiber fuse phenomenon in single-mode optical fibers, in Electronics and Communications in Japan, Part 2 2003; 86(11): 11-20.

[68] Y. Shuto, S. Yanagi, S. Asakawa, M. Kobayashi, and R. Nagase. Evaluation of high-temperature absorption coefficients of optical fibers, IEEE Photon. Technol. Lett. 2004; 16(4): 1008-1010.

[69] Y. Shuto, S. Yanagi, S. Asakawa, M. Kobayashi, and R. Nagase. Fiber fuse phenomenon in step-index single-mode optical fibers, IEEE J. Quantum Electron. 2004; 40(8): 1113-1121.

[70] Y. Shuto. Heat conduction modeling of fiber fuse in single-mode optical fibers, J. Photon. 2014; Vol. 2014, Article ID 645207: 1-21.

[71] H. L. Schick. A thermodynamic analysis of the high-temperature vaporization properties of silica, Chem. Rev. 1960; 60: 331-362.

[72] E. M. Dianov, I. A. Bufetov, and A. A. Frolov. Destruction of silica fiber cladding by the fuse effect, Opt. Lett. 2004; 29(16): 1852-1854. 
[73] H. R. Philipp. Optical properties of non-crystalline $\mathrm{Si}, \mathrm{SiO}, \mathrm{SiO}_{x}$ and $\mathrm{SiO}_{2}, J$. Phys. Chem. Solids 1971; 32: 1935-1945.

[74] H. R. Philipp. Optical and bonding model for non-crystalline $\mathrm{SiO}_{x}$ and $\mathrm{SiO}_{x} \mathrm{~N}_{y}$ materials, J. Non-Cryst. Solids 1972; 8-10: 627-632.

[75] W. J. Moore. Physical Chemistry. 4th Ed. Chap. 8. Prentice-Hall, Inc.; New York: 1972.

[76] JANAF Thermochemical Tables. 2nd Ed. U.S. Department of Commerce and National Bureau of Standards: 1971.

[77] M. H. Brodsky, R. S. Title, K. Weiser, and G. D. Pettit. Structural, optical, and electrical properties of amorphous silicon films, Phys. Rev. B 1970; 1(6): 2632-2641.

[78] D. L. Dexter. Interpretation of Urbach's rule, Phys. Rev. Lett. 1967; 19(24): 1383-1385.

[79] H. Mahr. Ultraviolet absorption of KI diluted in KCl crystals, Phys. Rev. 1962; 125(5): 1510-1516.

[80] G. G. Macfarlane and V. Roberts. Infrared absorption of silicon near the lattice edge, Phys. Rev. 1955; 98(6): 1865-1866.

[81] G. G. Macfarlane, T. P. McLean, J. E. Quarrington, and V. Roberts. Fine structure in the absorption-edge spectrum of Si, Phys. Rev. 1958; 111(5): 1245-1254.

[82] E. Burstein, G. Picus, and N. Sclar. Optical and photoconductive properties of silicon and germanium, in Photoconductivity Conference. pp. 353-413. John Wiley \& Sons, Inc.; New York: 1956.

[83] H. S. Carslaw and J. C. Jaeger. Conduction of Heat in Solids. 2nd Ed. Chap. 13. Oxford University Press; Oxford: 1959.

[84] I. Barin and O. Knacke. Thermochemical Properties of Inorganic Substances. p. 690. Springer-Verlag; Berlin: 1973.

[85] M. Shoji. Heat Transfer Textbook. Chap. 2. Univ. Tokyo Press; Tokyo: 1995.

[86] T. Okuda. Plasma Engineering. Chap. 3. Corona-Sha; Tokyo: 1975.

[87] T. Okuda. Plasma Engineering. Chap. 1. Corona-Sha; Tokyo: 1975.

[88] L. Spitzer, Jr. Physics of Fully Ionized Gases. 2nd Ed. p. 128. John Wiley \& Sons, Inc.; New York: 1962.

[89] G. D. Smith. Numerical Solution of Partial Differential Equations: Finite Difference Methods. 3rd Ed. Chap. 2. Clarendon Press; Oxford: 1985.

[90] E. M. Dianov, V. E. Frotov, I. A. Bufetov, V. P. Efremov, A. E. Rakitin, M. A. Melkumov, M. I. Kulish, and A. A. Frolov. Temperature of optical discharge under action of laser radiation in silica-based fibers, Proc. Eur. Conf. Opt. Commun. 2005: Vol. 3: 469-470 (We3.4.4). 
[91] Y. Shuto. Evaluation of high-temperature absorption coefficients of ionized gas plasmas in optical fibers, IEEE Photon. Technol. Lett. 2010; 22(3): 134-136.

[92] L. Spitzer, Jr. Physics of Fully Ionized Gases. 2nd Ed. Chap. 5. John Wiley \& Sons, Inc.; New York: 1962.

[93] Y. B. Zel'dovich and Y. P. Raizer. Physics of Shock Waves and High-Temperature Hydrodynamic Phenomena. Chap. 5. Dover; New York: 2002.

[94] T. Sekiguchi. Plasma Engineering. Chap. 1. Ohm-Sha; Tokyo: 1997.

[95] G. R. Fowles. Introduction to Modern Optics. 2nd Ed. Chap. 7. Dover; New York: 1975.

[96] S. P. Timoshenko and J. N. Goodier. Theory of Elasticity. 3rd Ed. p. 71. McGraw-Hill Book Co.; New York: 1970.

[97] T. Yokobori. An Interdisciplinary Approach to Fracture and Strength of Solids. Chap. 1. Gordon \& Breach Publishers; Amsterdam: 1968.

[98] H. Kobayashi. Fracture Mechanics. Chap. 3. Kyoritsu Press Ltd.; Tokyo: 1993.

[99] I. A. Bufetov, A. A. Frolov, A. V. Shubin, M. E. Likhachev, S. V. Lavrishchev, and E. M. Dianov. Propagation of an optical discharge through optical fibres upon interference of modes, Quantum Electron. 2008; 38(5): 441-444.

[100] K. Kurokawa and N. Hanzawa. Suppression of fiber fuse propagation and its break in compact fiber fuse terminator, OptoElectron. Commun. Conf. held jointly with 2013 Int. Conf. on Photonics in Switching 2013 (OECC/PS 2013): WS4-5.

[101] J. P. Gordon, R. C. C. Leite, R. S. Moore, S. P. S. Porto, and J. R. Whinnery. Long-transient effects in lasers with inserted liquid samples. J. Appl. Phys. 1965; 36(1): 3-8. 
